\title{
The Role of the Activator Additives Introduction Method in the Cold Sintering Process of ZnO Ceramics: CSP/SPS Approach
}

\author{
Yurii D. Ivakin ${ }^{1,2}$, Andrey V. Smirnov ${ }^{2,3}$, Alexandra Yu. Kurmysheva ${ }^{4, *}$, Andrey N. Kharlanov ${ }^{1}$, \\ Nestor Washington Solís Pinargote ${ }^{4}\left(\mathbb{D}\right.$, Anton Smirnov ${ }^{4}(\mathbb{D}$ and Sergey N. Grigoriev 4 (D) \\ 1 Chemistry Department, M. V. Lomonosov Moscow State University, 119991 Moscow, Russia; \\ ivakin@kge.msu.ru (Y.D.I.); Kharl@kge.msu.ru (A.N.K.) \\ 2 Mobile Solutions Engineering Center, MIREA-Russian Technological University, 119454 Moscow, Russia; \\ smirnov_av@mirea.ru \\ 3 Center for Design, Manufacturing and Materials, Skolkovo Institute of Science and Technology, \\ Bolshoy Boulevard 30, build. 1, 121205 Moscow, Russia \\ 4 Laboratory of Electric Current Assisted Sintering Technologies, Moscow State University of Technology \\ “STANKIN", Vadkovsky per. 1, 127055 Moscow, Russia; nw.solis@stankin.ru (N.W.S.P.); \\ a.smirnov@stankin.ru (A.S.); s.grigoriev@stankin.ru (S.N.G.) \\ * Correspondence: a.kyrmisheva@stankin.ru
}

check for updates

Citation: Ivakin, Y.D.; Smirnov, A.V.; Kurmysheva, A.Y.; Kharlanov, A.N.; Solís Pinargote, N.W.; Smirnov, A.; Grigoriev, S.N. The Role of the Activator Additives Introduction Method in the Cold Sintering Process of ZnO Ceramics: CSP/SPS

Approach. Materials 2021, 14, 6680.

https://doi.org/10.3390/ma14216680

Academic Editor: Eugene Olevsky

Received: 24 September 2021

Accepted: 3 November 2021

Published: 5 November 2021

Publisher's Note: MDPI stays neutral with regard to jurisdictional claims in published maps and institutional affiliations.

Copyright: (c) 2021 by the authors. Licensee MDPI, Basel, Switzerland. This article is an open access article distributed under the terms and conditions of the Creative Commons Attribution (CC BY) license (https:/ / creativecommons.org/licenses/by/ $4.0 /)$.

\begin{abstract}
The great prospects for introducing the cold sintering process (CSP) into industry determine the importance of finding approaches to reduce the processing time and mechanical pressure required to obtain dense ceramics using CSP. The introducing zinc acetate into the initial $\mathrm{ZnO}$ powder of methods, such as impregnation, thermovapor autoclave treatment (TVT), and direct injection of an aqueous solution into a die followed by cold sintering process using a spark plasma sintering unit, was studied. The effect of the introduction methods on the density and grain size of sintered ceramics was analyzed using SEM, dynamic light scattering, IR spectroscopy, and XRD. The impregnation method provides sintered samples with high relative density (over 0.90) and significant grain growth when sintered at $250{ }^{\circ} \mathrm{C}$ with a high heating rate of $100{ }^{\circ} \mathrm{C} / \mathrm{min}$, under a uniaxial pressure of $80 \mathrm{MPa}$ in a vacuum, and a short isothermic dwell time $(5 \mathrm{~min})$. The TVT and aqueous solution direct injection methods showed lower relative densities ( 0.87 and 0.76 , respectively) of CSP ZnO samples. Finally, the development of ideas about the processes occurring in an aqueous medium with CSP and TVT, which are subject to mechanical pressure, is presented.
\end{abstract}

Keywords: oxide ceramics; zinc oxide; cold sintering process; thermovapor treatment; microstructure; spark plasma

\section{Introduction}

In recent decades, significant progress in the evolution of promising new sintering methods has been made. For example, certain methods, such as FLASH sintering [1], spark plasma sintering (SPS) technologies [2-4], modified SPS [5], and cold sintering processes [6] have been developed. Common to all these new approaches is the emphasis on reducing the sintering time and temperature, and this can be considered as an advantage that favors a reduction in energy consumption [7] and consequently the emission of $\mathrm{CO}_{2}$ into the atmosphere [8], which is one of the great problems for the planet. On the other hand, a significant reduction in temperature and sintering time allows the consolidation of volatile and metastable phases, and the obtaining of unconventional microstructures provides the possibility of producing new materials with improved functional properties. Thus, new sintering technologies can have a decisive impact on the fields of biomaterials, electronics, communication systems, nuclear waste encapsulation, energy production and storage, electromechanical devices, and catalysis [9].

One of the most important innovations of the last decade has been the cold sintering process (CSP) [6]. Baba Heidary et al. [10] demonstrated that a reduction of sintering 
temperature and energy consumption during the cold sintering process can reach hundreds of degrees Celsius and two orders of magnitude, respectively, compared to traditional high-temperature sintering processes.

The principle of CSP could be summarized as a powder mixture (generally ceramic oxide) that, in combination with a liquid phase (generally water), is uniaxially pressed (50-500 $\mathrm{MPa}$ ) in a die and sintered at a temperature that is generally below $350{ }^{\circ} \mathrm{C}$ [11]. CSP differs from the well-known hydrothermal hot pressing (HHP) process [12] since the latter is limited to obtaining a comparatively narrow nomenclature of ceramic materials (silicon oxide-based materials, hydroxyapatite based bioceramics, zirconium oxide, and radioactive waste [9]), which are formed during hydrothermal chemical reactions at high mechanical pressure and with long residence times (up to several tens of hours).

CSP can be considered as a significant evolution of the HHP process, although both methods have common features: using an aqueous medium, uniaxial pressing, and temperatures below $500{ }^{\circ} \mathrm{C}$. The key difference between CSP and HHP is that in CSP a sealed reactor is not used (the sample does not experience hydrothermal conditions). Thus, the liquid is a metastable transition phase, and is squeezed out and evaporates from the working volume over time. From this point of view, the difference between CSP and HHP is purely technological, and both processes probably have common stages in terms of the mechanism $[6,9]$.

Unlike HPP, CSP is a universal process in terms of the breadth of materials obtained. Currently, the main possibility of sintering of more than 50 material compositions (mainly based on ceramic oxides) using the cold sintering process has been experimentally confirmed. These material compositions include microwave dielectrics, ferroelectrics, structural ceramics, lithium ion cathodes, solid state electrolytes, semiconductors, ceramic adhesives, magnetic ceramics, and inorganic glass [13].

The most important scientific problem is the lack of generally accepted and experimentally confirmed ideas about the mechanisms of CSP. From a practical point of view, the potential compatibility of CSP with large-scale industrial productions is of great importance. Despite a lack of understanding of the mechanisms of the CSP, attempts are being made to overcome the technological problems related with the use of long-term dwelling under high mechanical pressures in order to obtain dense ceramics parts [13]. The two tasks can be distinguished to solve this issue: reducing the applied mechanical pressure (or eliminating it) and reducing the CSP time. Gonzalez-Julian et al. [14] showed the fundamental possibility of using SPS machines for CSP in order to obtain dense ceramics at low temperatures in a short time, using high heating rates $\left(100{ }^{\circ} \mathrm{C} / \mathrm{min}\right)$ and a short dwell time (5 $\mathrm{min})$. However, the CSP in these conditions required a pressure greater than $100 \mathrm{MPa}$, which requires the use of a special steel die, since the standard graphite die did not allow it to withstand mechanical pressures of that magnitude.

Bang et al. [15] focused on a size scale-up CSP demonstrated the fundamental possibility of obtaining ceramics and composites based on $\mathrm{ZnO}, \mathrm{Li}_{1.5} \mathrm{Al}_{0.5} \mathrm{Ge}_{1.5}\left(\mathrm{PO}_{4}\right)_{3}$ and zeolite using CSP at a pressure below $50 \mathrm{MPa}$, but with long dwell times from 15 to $480 \mathrm{~min}$. This result is an important step in the industrial implementation of the CSP method. However, an increase in the size of the samples led to microstructural inhomogeneity, which can be caused by randomly localized evaporation of the transition liquid phase. Currently, the search for approaches to simultaneously accelerate CSP and reduce the mechanical pressure continues to be an urgent topic of research.

The most detailed data on the effect of the type and amount of the activating additive, temperature, pressure, and powder characteristics on the density and grain size of cold sintered ceramics are available for $\mathrm{ZnO}$ [14-22]. However, the degree of influence of the activator's introduction method, when using water as a transport phase, remains poorly studied. In our previous work [20], a high mechanical pressure (up to $396 \mathrm{MPa}$ at the compaction stage and $77 \mathrm{MPa}$ at dwell stage), slow heating rate $\left(250{ }^{\circ} \mathrm{C}\right.$ during $40 \mathrm{~min}$. $)$, and long dwell time $(1 \mathrm{~h})$ were used. Furthermore, it was shown that the introduction of zinc acetate by both $\mathrm{ZnO}$ powder impregnation method and the traditional method 
of acetate introduction in an aqueous solution does not change the CSP results while maintaining identical amounts of activator and water.

In addition, in another previous work [21] it was shown that there is a similarity in the conditions of the crystal structure transformation of $\mathrm{ZnO}$ in both the water vapor medium at CSP and the autoclave thermovapor treatment (TVT).

The study of the oxide crystal formation process in pre- and supercritical aqueous media led to the idea of the appearance of solid-phase mobility of the crystal structure under TVT conditions in the presence of an activator. This additive facilitates the interaction of crystals with the medium. The solid-phase mobility appears due to exchange processes between crystals and the medium [21,23]. At the same time, mass transfer and crystal growth begin. The interaction of the activating additive with the initial powder during the TVT process leads to the surface and volume changes in the powder particles crystal structure $[21,23,24]$. The use of a raw material previously subjected to TVT can drastically change the results obtained after CSP compared to other traditional methods of activator introduction that are applied just before starting the CSP, such as direct powder mixing with water solution [22]; mixing ceramic and activator powders with subsequent water addition [25], and direct solution injecting into the die [14]. The study of the process features in such experimental conditions is important both in the context of the applied aspect and for the development of ideas about the existing CSP mechanisms. Guo et al. [6] proposed a CSP mechanism for ceramics densification that has received greater recognition in the scientific community and whose the main stage is mass transfer by dissolutionprecipitation $[10,12]$. According to this model, three stages of compaction under the influence of mechanical pressure are considered: (i) the rearrangement of particles, which is facilitated by the liquid phase; (ii) grain growth; and (iii) pore removal. Stages (ii) and (iii) occur due to the dissolution of the solid phase in areas with high mechanical stress of contacting particles, followed by deposition on contactless surfaces with low mechanical stress [6]. However, subsequent studies have shown that more complex mechanisms are involved in the process of cold sintering, which is not yet fully understood [14,26]. Afterwards, it was noted that there is a problem in the re-deposition model: dissolution and precipitation are exclusively surface events and can only lead to particle enlargement but cannot contribute to their compaction [14,21]. Guo et al. [12] established that the liquid volume necessary for the formation of ceramics in CSP is only approximately $5 \mathrm{vol} . \%$ of powder, and the liquid was called "The transport phase", since the analogy of liquid-phase sintering. Gonzalez-Julian et al. [14] revealed that $\mathrm{ZnO}$ sintering occurs in the presence of $1.6 \mathrm{wt} . \%$ water, which corresponds to only two water monolayers on the particles surface and it is not enough for the dissolution-precipitation processes. Moreover, the authors noted that half of $1.6 \mathrm{wt} . \%$ water dissociates and diffuses into the oxide lattice, increasing the defectiveness of crystals and grain boundaries. Floyd et al. [27] demonstrated that during CSP of $\mathrm{ZnO}$ in the presence of the crystalline additive $\mathrm{Zn}(\mathrm{Ac})_{2} \cdot 2 \mathrm{H}_{2} \mathrm{O}$, used as the transport phase, the mass transfer is not associated with the added liquid water, but is related to the adsorbed water and structural water of the additive. In addition to this, the authors did not consider the action mechanism of the transport phase but supposed that it enhances surface diffusion and grain growth. Considering the above this effect, the compaction during CSP was explained as a decrease in the diffusion activation energy of atoms along grain boundaries due to the high concentration of hydroxyl ions and other defects formed due to dissociative adsorption of water [14,26-29]. Further, starting with the work [30], the mass transfer due to surface diffusion is actively discussed in the literature. As a result, when describing the mass transfer stage in the CSP model, the emphasis was shifted from the dissolution-precipitation mechanism to the surface diffusion mechanism. In addition, in our works [21,23], the explanation of the CSP mechanism is based on the idea of the solid-phase mobility of the crystal structure, which occurs due to the intensive exchange of water and activator molecules between the environment and the dissociated forms of these molecules bound in the volume of crystals. To further develop the CSP mechanism's understanding, it is important to obtain, systematize, and analyze 
as much new experimental data as possible. In particular, to study the effects of various CSP conditions.

The present work aims to study the effect of the activator's introduction method on the grain size and density of $\mathrm{ZnO}$ ceramics obtained in a short time and under a lower-pressure CSP using SPS equipment. The CSP/SPS experiments were carried out under the same composition and density conditions of the aqueous medium studied in previous works $[20,21,23]$, but with a significantly higher heating rate and a short dwell time. The durations of the heating and holding stages (40 and $60 \mathrm{~min}$, respectively, were used in $[20,21,23])$ differed by an order of magnitude compared with the values used in this study (2 and $5 \mathrm{~min}$, respectively). Comparing the results obtained under conditions of a significant change in the time factor reveals the role of different stages of the CSP mass transport mechanism. In addition, reducing the CSP time is important in reducing the process's energy consumption. The obtained results also revealed the role of the activator additives introduction method on the CSP/SPS process features. This paper describes for the first time the results of using TVT as a method of introducing an activator additive into $\mathrm{ZnO}$ powder for CSP. In previous works $[20,21,23]$ and this study, the same initial $\mathrm{ZnO}$ powder and other reagents were used. The impregnated powder and TVT samples were prepared each time anew immediately before the experiment.

\section{Materials and Methods}

\subsection{Composites Preparation}

In the present work ZnO powder (JSC "St. Petersburg Red Chemist", Russia) with a mean particle size of $0.2 \mu \mathrm{m}$ and solid zinc acetate $\mathrm{Zn}\left(\mathrm{CH}_{3} \mathrm{COO}\right)_{2} \cdot 2 \mathrm{H}_{2} \mathrm{O}$ (LLC "Prime Chemicals Group", Russia) were used as starting materials. All reagents had a purity of the main component of $>99 \mathrm{wt}$. $\%$ according to the supplier's documentation.

The solid zinc acetate $\mathrm{Zn}(\mathrm{Ac})_{2}$ activating additive $0.5 \mathrm{wt} . \%$ or $0.185 \mathrm{~mol} \%, 2.5 \mathrm{wt}$ \% or $0.927 \mathrm{~mol} \%$, and $5 \mathrm{wt} . \%$ or $1.853 \mathrm{~mol} \%$ was introduced into the raw powder in three ways:

- $\quad$ injecting the activator solution using a syringe directly into the die with pre-pressed $\mathrm{ZnO}$ powder, similar to [14];

- $\quad$ preliminary application by impregnation method;

- $\quad$ TVT of ZnO powder previously impregnated by $\mathrm{Zn}(\mathrm{Ac})_{2}$.

When $\mathrm{Zn}(\mathrm{Ac})_{2}$ was applied by impregnation, $20 \mathrm{~g}$ of $\mathrm{ZnO}$ powder was mixed during treatment in an ultrasonic bath with $30 \mathrm{~mL}$ of an activator solution in distilled water. The obtained wet mixture was dried at $70{ }^{\circ} \mathrm{C}$ for $12 \mathrm{~h}$. The resulting powder was ground in an agate mortar and subsequently passed through a $300-\mu \mathrm{m}$ sieve.

TVT was performed in $17 \mathrm{~mL}$ laboratory autoclaves (self-made) using a copper gasket and Teflon containers with a loose-fitting lid. The container was installed in an autoclave on a stand that the water does not get into the container with dry powder, and the process goes only in water vapor. Water was poured into the bottom of the autoclave below a container's stand. 1-5 g of $\mathrm{ZnO}$ powder previously impregnated by $\mathrm{Zn}(\mathrm{Ac})_{2}$ was placed in the container. The autoclave was sealed, heated in a furnace to $220^{\circ} \mathrm{C}$, and held for $20 \mathrm{~h}$. With such loading of the autoclave, heating and isothermal dwelling of $\mathrm{ZnO}$ occurred in a water vapor environment-under TVT conditions. The peculiarities of TVT are described in [21]. The content of the additive in the reaction medium was calculated in wt. $\%$ relative to $\mathrm{ZnO}$.

\subsection{Cold Sintering Process}

CSP was carried out using the SPS technique H-HP D 25 (FCT Systeme, GmbH, Rauenstein, Germany). The powder pre-pressing was realized on the 12 tons Manual Hydraulic Press Test System (Carver, Inc., Wabash, IN, USA). Graphite punches and die with an inner diameter of $20 \mathrm{~mm}$, and graphite foil were used. For reproducibility of control of the heating conditions in each experiment, a thermocouple was installed in a die wall a distance of $5 \mathrm{~mm}$ from the inner wall of die. 
CSP samples preparation: the initial $\mathrm{ZnO}$ powder was mixed with deionized water similar to the procedure described in the article [15]. For this, $3 \mathrm{~g}$ of $\mathrm{ZnO}$ powder was poured into a die and prepressed on a hand press with a pressure of $16 \mathrm{MPa}$, the upper punch was removed, and then in the center of the pre-pressed powder pellet with a thickness of $0.34-0.50 \mathrm{~mm}$ the $0.05 \mathrm{~mL}(1.6 \mathrm{wt} . \%)$ deionized water was added using a micro syringe (injecting). If possible, the drop was directed to the center of the pre-pressed pellet. Next, a graphite foil disk and a punch were placed into the die. The assembled die was transferred to the SPS machine, and the CSP was started according to the program:

- $\quad$ Pressing up to $15 \mathrm{MPa}$.

- Evacuation process (0.23 mbar vacuum).

- $\quad$ Pressing up to $50 \mathrm{MPa}$.

- Heating rate $100^{\circ} \mathrm{C} / \mathrm{min}$.

- Pressing up to $80 \mathrm{MPa}$.

- Dwell time for $5 \mathrm{~min}$ at $80 \mathrm{MPa}$ and a temperature of $250{ }^{\circ} \mathrm{C}$.

- Cooling at a pressure of $15 \mathrm{MPa}$.

- Venting, extracting the mold.

The limiting pressure value is determined by the mechanical restrictions of the standard graphite tools, for instance, in [15] a steel die and punches were used for pressing at 100, 125, and $150 \mathrm{MPa}$.

\subsection{Density Measurements}

The calculation of the relative density was carried out according to the formula adopted from [25]:

$$
d_{r e l}(t)=\frac{m_{f}}{\pi \cdot r_{f}^{2} \cdot\left(t_{f}+\left(s_{\max }-s(t)\right)\right) \cdot \rho_{\text {theo }}}
$$

where $m_{f}, r_{f}$, and $t_{f}$-are, respectively, the mass, the radius, and the thickness of the final pellet; $s_{\max }, s(t)$ - the maximum shrinkage of sample and shrinkage at a certain point in time, respectively (according to process data from SPS setup); $\rho_{\text {theo }}$ - theoretical density of $\mathrm{ZnO}$ equal to $5.61 \mathrm{~g} / \mathrm{cm}^{3}$. The diameter and thickness of the samples were measured with a caliper and a micrometer after cleaning from graphite foil (Figure 1).

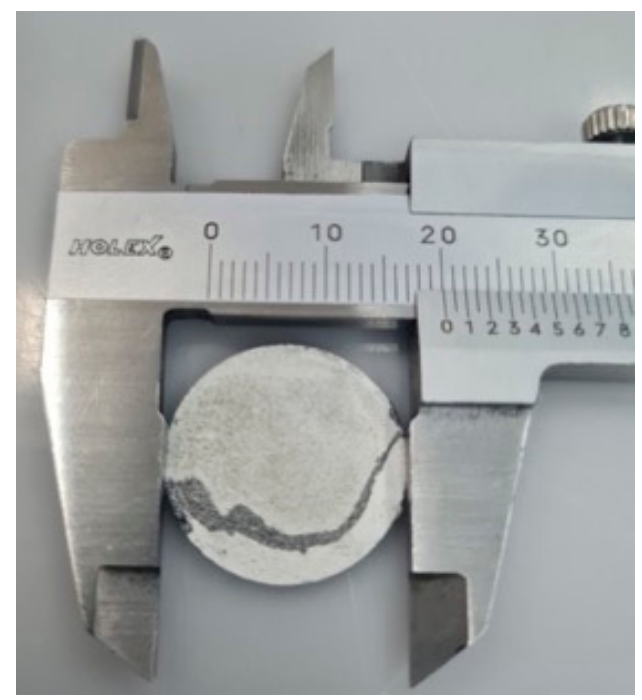

Figure 1. ZnO CSP sample.

\subsection{XRD Characterization}

XRD measurements of the powders and sintered samples (XRD-6000, Shimadzu Corp., Kyoto, Japan) were performed at diffraction angles of $2 \theta$ ranging from $5^{\circ}$ to $60^{\circ}$ (step scanning mode, step size $0.02^{\circ}$ ). Qualitative analysis was carried out by comparing 
experimental patterns with data from the database. The conclusion about the presence of layered basic zinc acetate (LBZA) was made according to [31].

\subsection{Microstructural Characterization}

Morphologic properties of the powder particles and sintered samples were evaluated by scanning electron microscope (SEM) JSM-6390 LA (JEOL Ltd., Tokyo, Japan) in the backscattered measurement mode. Particle size analysis was carried out by dynamic light scattering (DLS) in a Photocor Compact equipment (LLC Photocor, Moscow, Russia) after preliminary ultrasonic deagglomeration of an aqueous suspension within two minutes. The particle size distribution (PSD) was performed by SEM images analysis using the lognormal particle size distribution function [32]. Mean particle size $\mathrm{D}$ was determined by simply averaging over all measured objects in the sample. The Image-Pro software (Media Cybernetics, Rockville, MD, USA) was used to determine the size of 2000 to 3000 particles in each sample. The state change of the $\mathrm{ZnO}$ crystals after the $\mathrm{Zn}(\mathrm{Ac})_{2}$ addition was monitored by diffuse reflectance infrared Fourier transform spectroscopy (DRIFTS) in the range $400-7500 \mathrm{~cm}^{-1}$ (IR Fourier spectrometer EQUINOX 55/S, Bruker Co., Billerica, MA, USA).

\section{Results}

The results of experimental studies are presented in the following sequence: first, the characterization of the raw $\mathrm{ZnO}$ powder is presented, then it is followed by the effect description of two activator introduction methods (impregnation and impregnation + subsequent TVT) and activator concentrations on the raw powder size, morphology, and phase composition; second the characteristics of $\mathrm{ZnO}$ ceramic samples obtained by CSP from the powders described in the previous subsection are presented.

\subsection{The Effect of Activator Introduction Method on the Initial $\mathrm{ZnO}$ Powder Characteristics}

Summary data on measuring the particle sizes of $\mathrm{ZnO}$ powders after their impregnation with $\mathrm{Zn}(\mathrm{Ac})_{2}$ and after impregnation with subsequent TVT are presented in Table 1.

Table 1. Powder particle sizes measured by DLS and SEM image analysis.

\begin{tabular}{ccccc}
\hline \multirow{2}{*}{ Sample } & $\begin{array}{c}\text { Zn(Ac) } \\
\text { Content, } \\
\text { wt\% }\end{array}$ & $\begin{array}{c}\text { Zn(Ac) } \\
\text { Introduction } \\
\text { Method }\end{array}$ & DLS, $\mathbf{d}_{\mathbf{5 0}}$ & SEM Image Analysis, D \\
\cline { 4 - 5 } & 0 & - & $0.210 \pm 0.004$ & $0.193 \pm 0.002$ \\
\hline ZnO initial & 0.5 & & $0.228 \pm 0.004$ & $0.181 \pm 0.002$ \\
0.5\%Ac/ZnO & 2.5 & Impregnation & $0.234 \pm 0.005$ & $0.194 \pm 0.003$ \\
2.5\%Ac/ZnO & 5 & & $0.245 \pm 0.005$ & $0.194 \pm 0.002$ \\
5\%Ac/ZnO & 0.5 & Impregnation + & $0.268 \pm 0.005$ & $0.369 \pm 0.004$ \\
\hline TVT_0.5\%Ac/ZnO & TVT & $0.291 \pm 0.006$ & $0.449 \pm 0.006$ \\
TVT_2.5\%Ac/ZnO & 2.5 & TV & $0.310 \pm 0.006$ & $0.449 \pm 0.006$ \\
TVT_5\%Ac/ZnO & 5 & & &
\end{tabular}

The difference in the average powder particle sizes, determined by two different methods, may cause the hydrodynamic diameter of the particles to be determined by DLS method and the influence of the residual agglomerates remaining after ultrasonic deagglomeration. In addition, the average size characteristic of DLS, $\mathrm{d}_{50}$ does not take into account changes in the levels of small and large particle sizes. Initial $\mathrm{ZnO}$ powder particles morphology is shown in Figure 2a. The average crystal size determined by SEM image analysis and DLS were $\mathrm{D}=0.193 \mu \mathrm{m}$ and $\mathrm{d}_{50}=0.210 \mu \mathrm{m}$, respectively. PSD is described by a lognormal function and consists of a single component. After applying $0.5 \mathrm{wt} . \% \mathrm{Zn}(\mathrm{Ac})_{2}(0.5 \% \mathrm{Ac} / \mathrm{ZnO}$ powder sample), the size range did not change, but there were a differentiation of the crystals with the appearance of two components of the PSD (Figure 2c,d) and a slight decrease in mean particle size D (Table 1) due to the 
appearance of a fine component PSD. The impregnation of the $\mathrm{ZnO}$ powder by $0.5 \mathrm{wt} . \%$ $\mathrm{Zn}(\mathrm{Ac})_{2}$ and the subsequent TVT also lead to a change in the PSD. However, during the TVT process, a complete separation of PSD into a finely dispersed component and the main group of crystals (powder particles) occurs, the mass transfer between which leads to the appearance of new components and an increase in the mean particle size D (Figures $2 \mathrm{f}$ and $3 \mathrm{~d}$ ). Moreover, the transfer of mass to the crystals of the finely dispersed component does not occur. With an increase in the content of $\mathrm{Zn}(\mathrm{Ac})$ up to $5 \mathrm{wt} . \%$, the separation of the fine component becomes more pronounced after impregnation, and the main proportion of crystals is divided into components without changing the mean particle size D (Figure 3a,b). After TVT, the finely dispersed component is completely separated from the main part of the crystals due to the redistribution of mass between them with an increase in the mean particle size D and the number of PSD components (Figure 3c,d). The bimodal nature of PSD can have a significant influence on the relative density of CSP samples obtained from powder samples after TVT (TVT_0.5\%Ac/ZnO, TVT_2.5\%Ac/ZnO, TVT_5\%Ac/ZnO) due to a denser packing of $\mathrm{ZnO}$ powder particles in a mold [33,34]. For samples impregnated without subsequent TVT $(0.5 \% \mathrm{Ac} / \mathrm{ZnO}, 2.5 \% \mathrm{Ac} / \mathrm{ZnO}, 5 \% \mathrm{Ac} / \mathrm{ZnO})$, the nature of PSD will have a minor effect on the relative density of CSP samples. Thus, the differentiation of crystals into components during impregnation occurs due to the formation of crystals of a finely dispersed component, and mass transfer is involved in the differentiation of the rest of the crystals during TVT. The change in the mean particle size D during impregnation and TVT is shown in Figure 4. It can be seen that as a result of the redistribution of mass at TVT, that the mean particle size D increases more than twice regarding the initial $\mathrm{ZnO}$ powder.

Figure 5 shows $\mathrm{XRD}$ diagrams of $\mathrm{ZnO}$ samples with 0.5 , 2.5, and $5 \mathrm{wt} . \% \mathrm{Zn}(\mathrm{Ac})_{2}$. After applying $\mathrm{Zn}(\mathrm{Ac})_{2}, \mathrm{Zn}_{5}(\mathrm{OH})_{8}\left(\mathrm{CH}_{3} \mathrm{COO}\right)_{2} \cdot 2 \mathrm{H}_{2} \mathrm{O}$ (layered basic zinc acetate (LBZA) [31] reflexes appear on the $\mathrm{XRD}$ diagrams of $\mathrm{ZnO}$ powder samples. The intensity of reflexes in the range of $2 \theta 5-30^{\circ}$, related to LBZA, increased by 10 times. The intensity of the main reflex of $2 \theta 6.5^{\circ}$ is proportional to the amount of acetate applied, while the reflex at $2 \theta \sim 13^{\circ}$ practically does not depend on its concentration. This may be caused to the lamellar morphology of LBZA and the variable size of the plates with a small change in their thickness. The disappearance of the LBZA reflexes indicates its decomposition during TVT and CSP. The $\mathrm{ZnO}$ reflexes in the range of $2 \theta 30-60^{\circ}$ are the same for all samples shown in Figure 5a-c.

Figure 6 shows the DRIFTS spectra of $\mathrm{ZnO}$ powder in the initial state, after application by impregnation of $5 \% \mathrm{Zn}(\mathrm{Ac})_{2}$ ( $5 \% \mathrm{Ac} / \mathrm{ZnO}$ powder sample) and after impregnation with subsequent TVT (TVT_5\%Ac/ZnO powder sample). The initial $\mathrm{ZnO}$ powder absorption bands in the region of $1000-7500 \mathrm{~cm}^{-1}$ refer to the adsorbed components of the atmosphere in which the powder was stored. The application of $\mathrm{Zn}(\mathrm{Ac})_{2}$ by the impregnation method leads to the appearance in the samples DRIFTS spectra of several absorption bands, which were absent from the initial $\mathrm{ZnO}$ powder (Figure 6). Absorption bands in the region of $4000-7500 \mathrm{~cm}^{-1}$ are not described in the literature. Valence vibrations of hydroxyl groups cause the absorption in a wide area with a maximum of about $3363 \mathrm{~cm}^{-1}$. After introducing of $5 \% \mathrm{Zn}(\mathrm{Ac})_{2}$ by both methods, the absorption in this area increases noticeably. The increase in absorption is associated with the hydroxylation of $\mathrm{ZnO}$ due to the dissociative adsorption of water molecules [35]. The bands of valence vibration of $\mathrm{CH}$ bonds at 2933 and $3011 \mathrm{~cm}^{-1}$ appear after impregnation of $5 \% \mathrm{Zn}(\mathrm{Ac})_{2}$ and impregnation with subsequent TVT. They are displaced relative to the usual positions of 2850 and $2920 \mathrm{~cm}^{-1}$ in $\mathrm{Zn}(\mathrm{Ac})_{2}$ [36]. The displacement of the peak positions is associated with the influence of the solid matrix on the state of the bonds and indicates the localization of these groupings inside the crystals. The peaks of the complex absorption band $\left(1336-1560 \mathrm{~cm}^{-1}\right)$ in the range of 1300-1600 $\mathrm{cm}^{-1}$ belong to the carboxylate group [37]. It should be noted that the width of these bands decreases after TVT, while the absorption bands at 5125 and $6980 \mathrm{~cm}^{-1}$, on the contrary, become wider. 


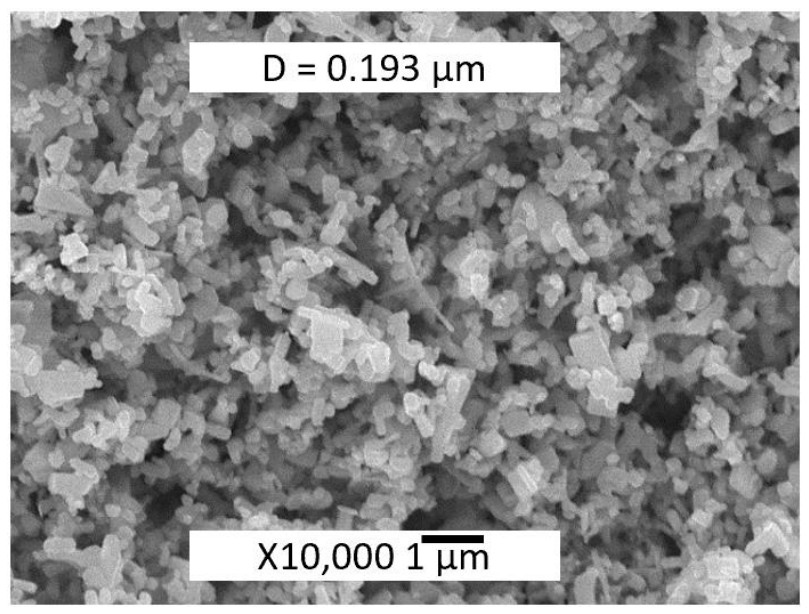

(a)

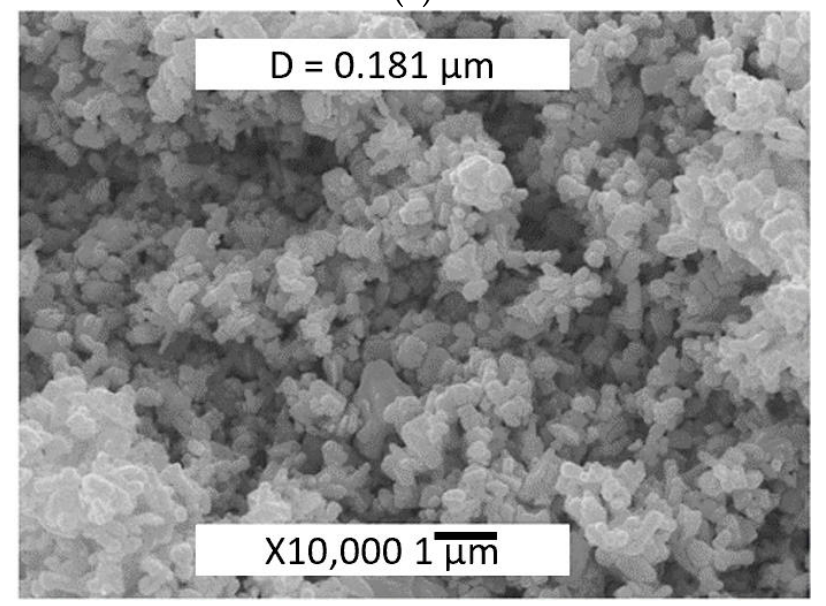

(c)

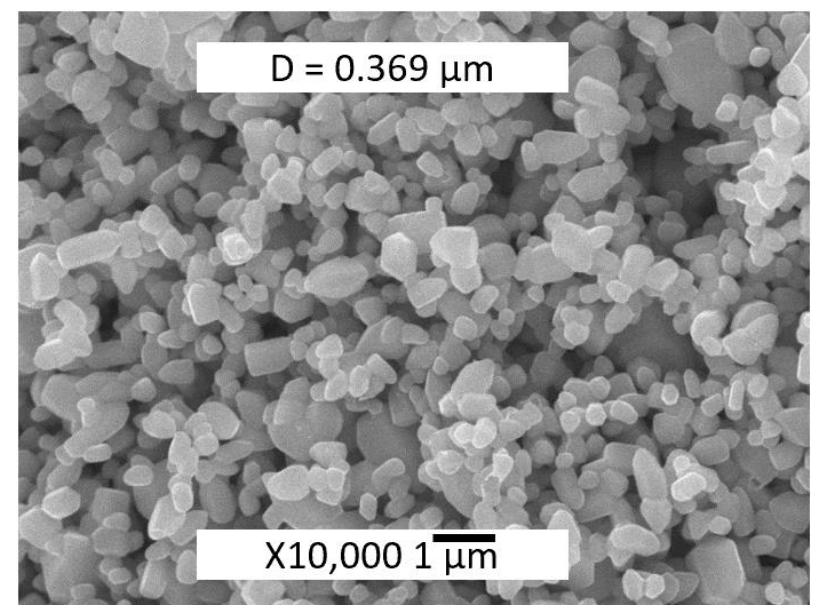

(e)

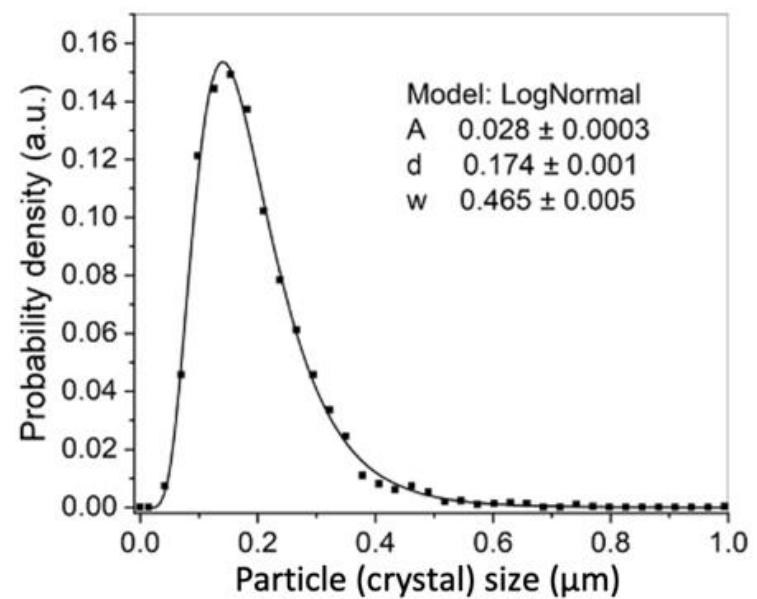

(b)

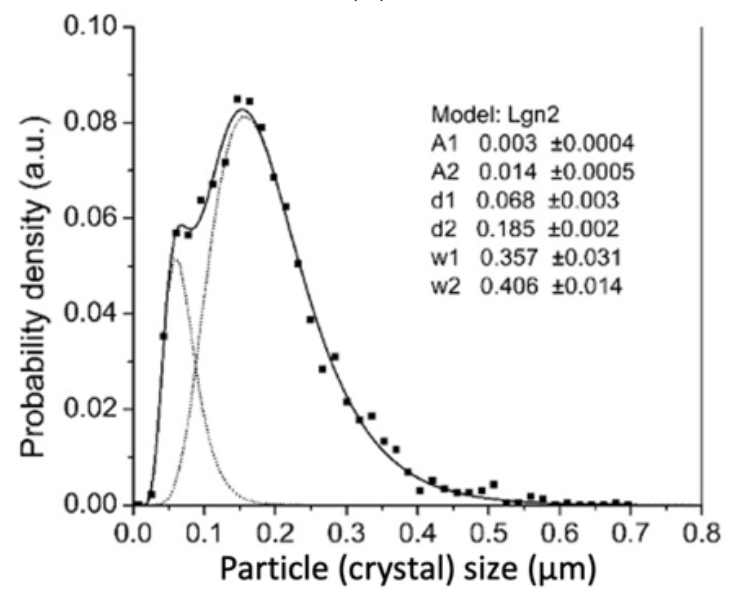

(d)

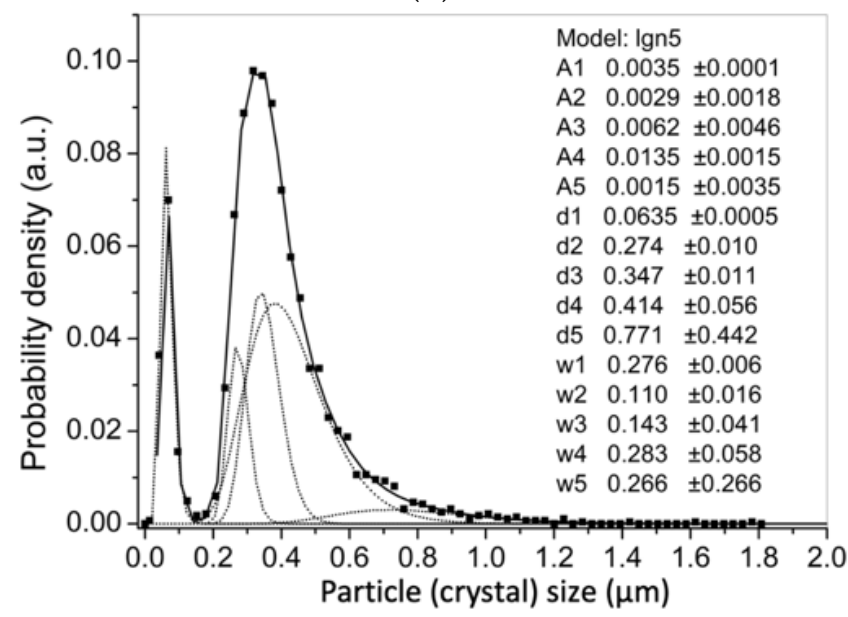

(f)

Figure 2. SEM image and PSD of $\mathrm{ZnO}$ powder in the initial state $(\mathbf{a}, \mathbf{b})$ after applying $0.5 \% \mathrm{Zn}(\mathrm{Ac})_{2}$ by impregnation $\left(0.5 \% \mathrm{Ac} / \mathrm{ZnO}\right.$ powder sample) $(\mathbf{c}, \mathbf{d})$, and applying $0.5 \% \mathrm{Zn}(\mathrm{Ac})_{2}$ by impregnation with subsequent TVT (TVT_0.5\%Ac/ZnO powder sample) (e,f). The PSD is calculated from the respective SEM images. 


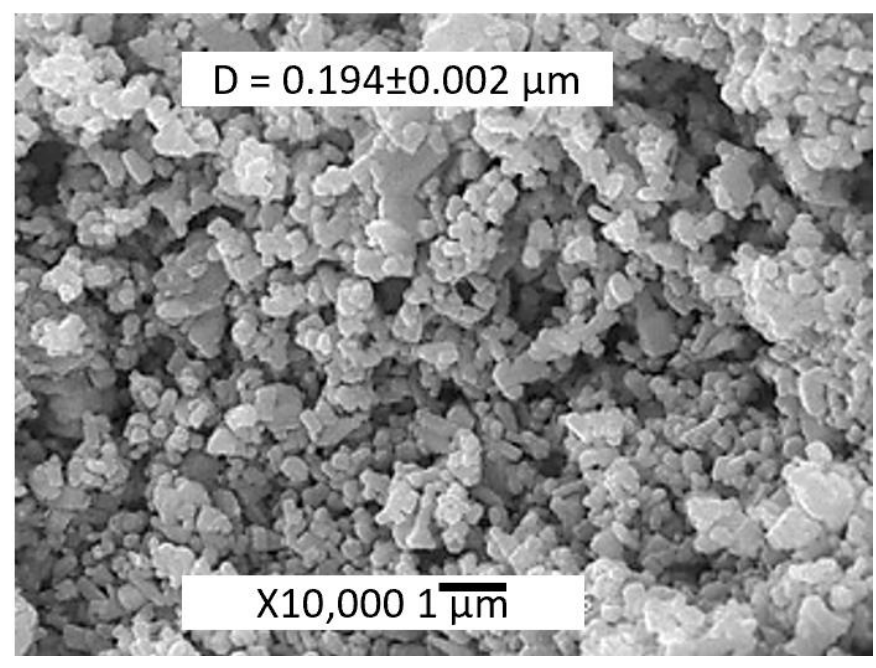

(a)

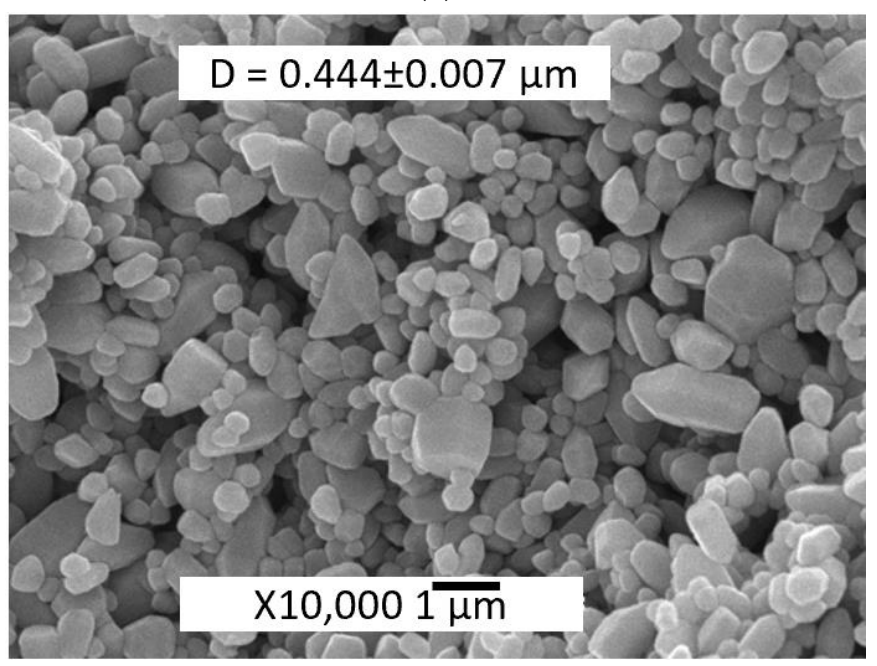

(c)

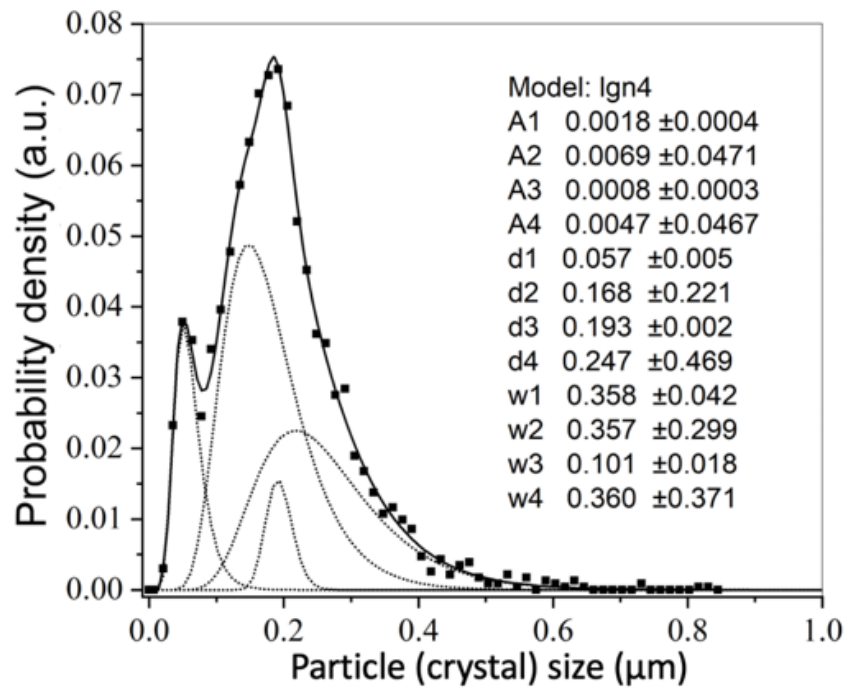

(b)

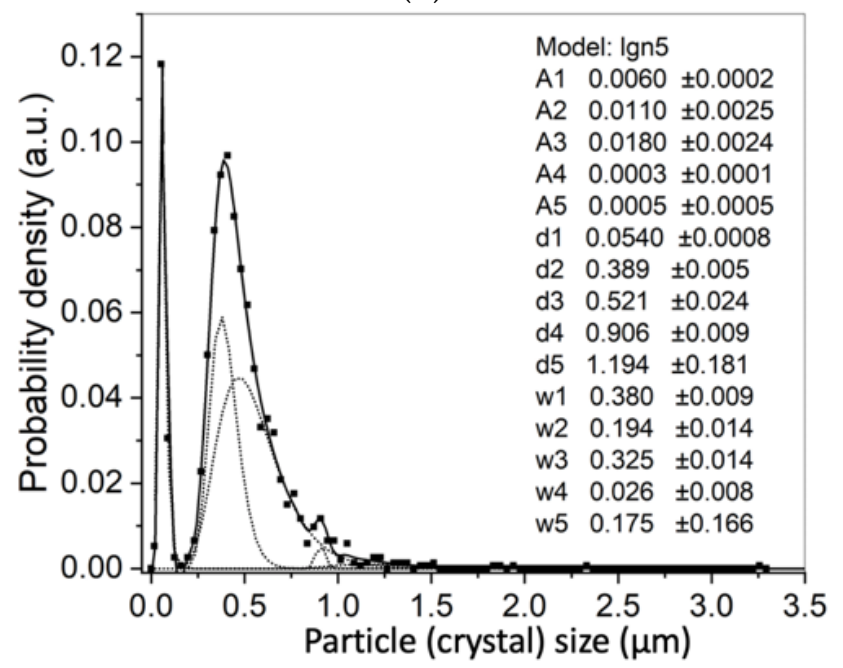

(d)

Figure 3. SEM images and PSD of $5 \% \mathrm{Ac} / \mathrm{ZnO}$ powder $(\mathbf{a}, \mathbf{b})$; and TVT_5\%Ac/ZnO powder (c,d). The PSD is calculated from the respective SEM images.

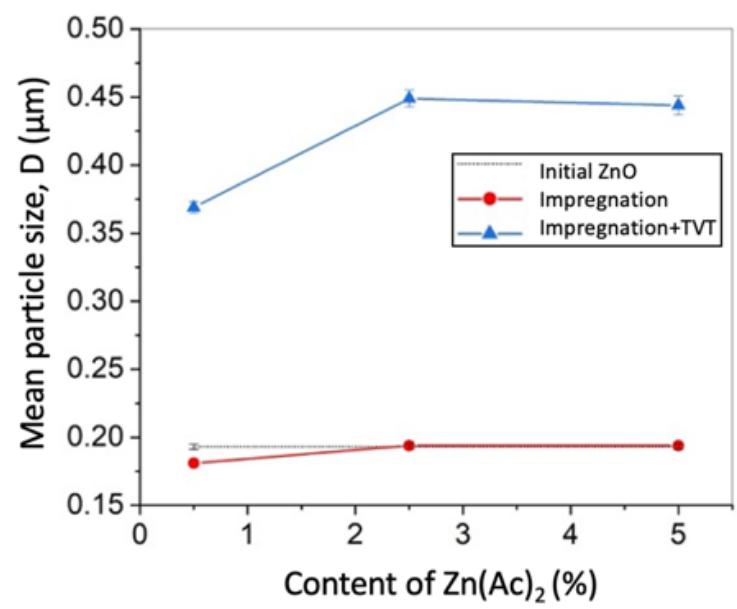

Figure 4. The dependence of the average crystal size on the content of $\mathrm{Zn}(\mathrm{Ac})_{2}$ during impregnation (1) and TVT (2): the dotted line-DLS method, the solid line-SEM images analysis method. 


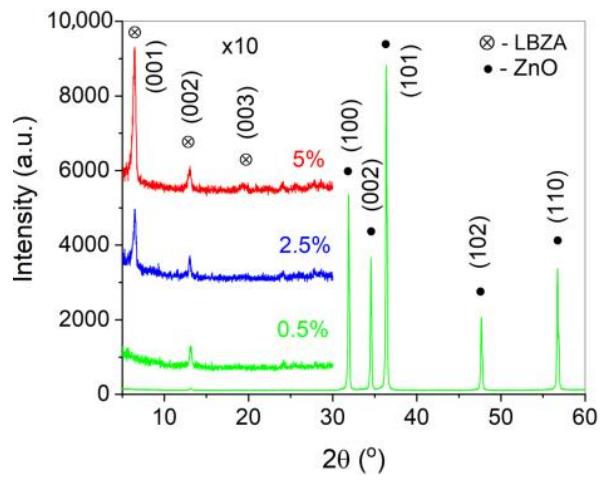

(a)

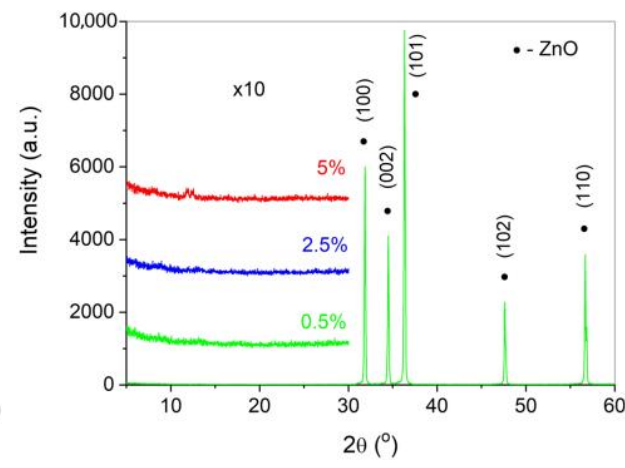

(b)

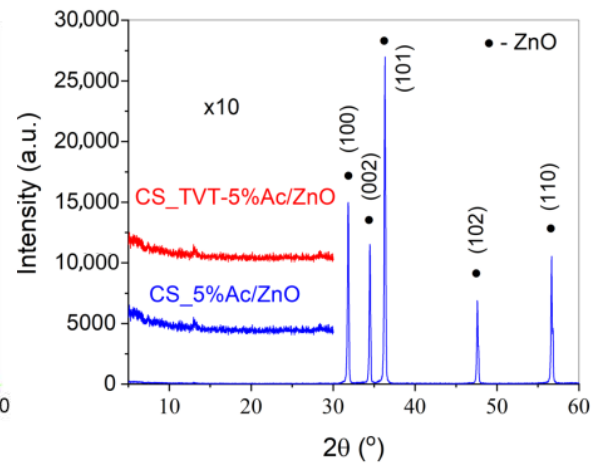

(c)

Figure 5. XRD diagrams of the powders after $\mathrm{Zn}(\mathrm{Ac})_{2}$ impregnation (a), after $\mathrm{Zn}(\mathrm{Ac})_{2}$ impregnation $+\mathrm{TVT}(\mathbf{b})$, and CSP samples (c). The reflexes intensity in the range of $2 \theta 5-30^{\circ}$ increased by 10 times.

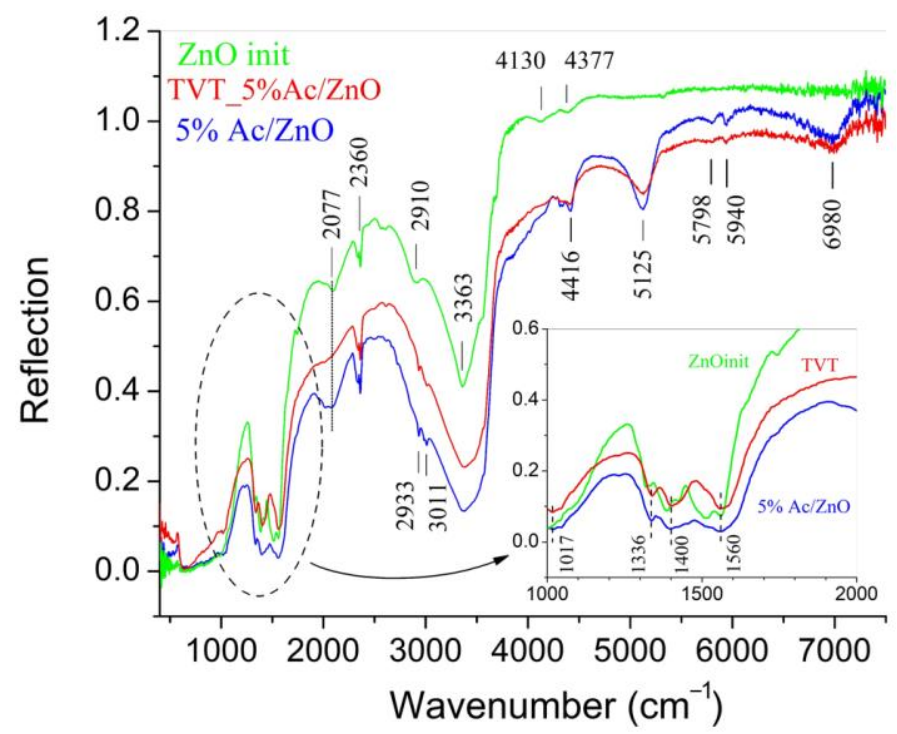

Figure 6. DRIFTS spectrum of $\mathrm{ZnO}$ powder in the initial state, after applying $5 \% \mathrm{Zn}(\mathrm{Ac})_{2}$ by impregnation (5\%Ac/ZnO) and impregnation + subsequent TVT (TVT_5\%Ac/ZnO).

The main result of TVT is the destruction of LBZA, the growth of crystals, and the improvement of the crystal $\mathrm{ZnO}$ structure, at which the content of hydroxyl groups decreases [38]. The decomposition of LBZA, observed according to the XRD analysis (Figure $5 b$ ), leads to a decrease in the intensity of the corresponding absorption bands, but all the bands are preserved in the IR spectrum. Consequently, traces of acetate remain in the crystal structure.

Figure 7 shows the spectra of additional absorption caused by a change in the $\mathrm{Zn}(\mathrm{Ac})_{2}$ content in samples that have undergone TVT. The additional absorption spectra are obtained by subtracting the spectrum of a sample with a lower $\mathrm{Zn}(\mathrm{Ac})_{2}$ content from the spectrum of a sample containing more $\mathrm{Zn}(\mathrm{Ac})_{2}: \Delta \mathrm{R}=\mathrm{R}\left(\mathrm{TVT} \_5 \% \mathrm{Ac} / \mathrm{ZnO}\right)$ $\mathrm{R}\left(\mathrm{TVT} \_2.5 \% \mathrm{Ac} / \mathrm{ZnO}\right)$ и $\Delta \mathrm{R}=\mathrm{R}\left(\mathrm{TVT} \_2.5 \% \mathrm{Ac} / \mathrm{ZnO}\right)-\mathrm{R}\left(\mathrm{TVT} \_0.5 \% \mathrm{Ac} / \mathrm{ZnO}\right)$.

It can be seen that with an increase in the $\mathrm{Zn}(\mathrm{Ac})_{2}$ content, the position of a number of bands remains mainly in the region of more than $4000 \mathrm{~cm}^{-1}$. The position of the bands in the regions belonging to the hydroxyl $\left(3000-4000 \mathrm{~cm}^{-1}\right)$ and carboxylate $\left(1200-1600 \mathrm{~cm}^{-1}\right)$ groups changes. This means that in the first case, with an increase in the $\mathrm{Zn}(\mathrm{Ac})_{2}$ content, the spectrum of states of the absorbing groups does not change. In the second case, the shift of the absorption bands reflects a change in the localization conditions of additional groupings in the $\mathrm{ZnO}$ crystal structure. 


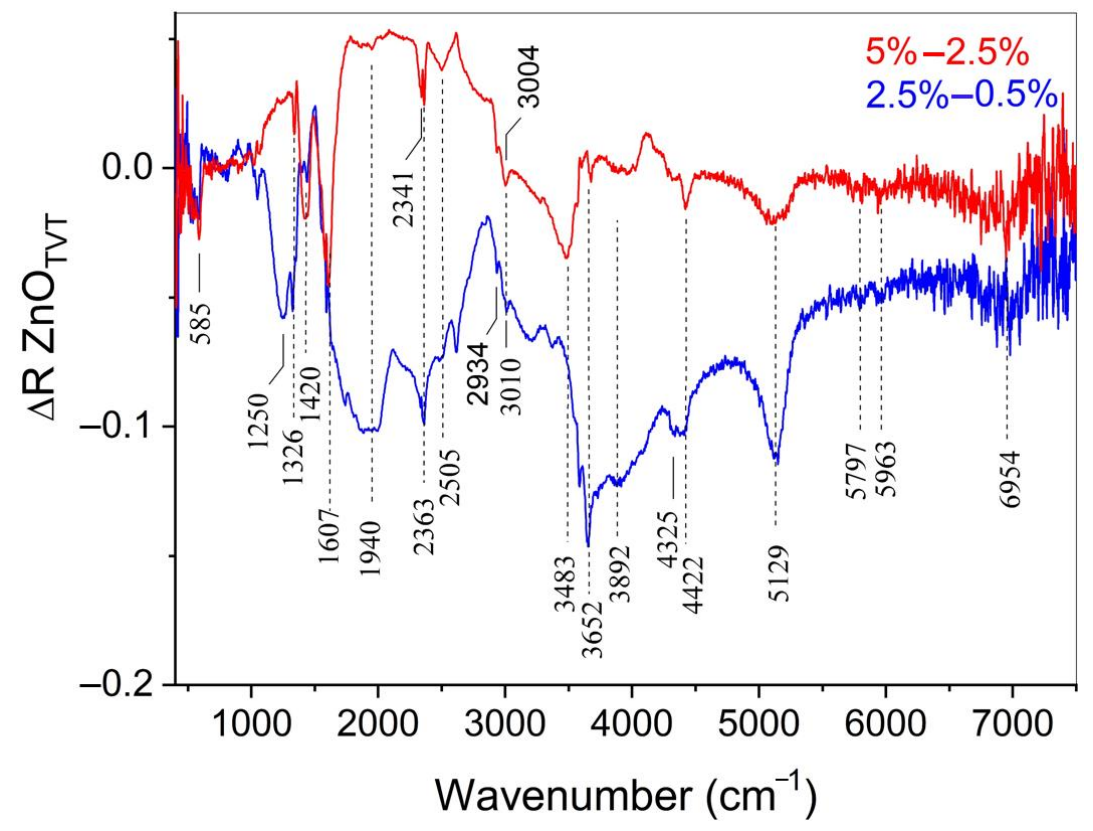

Figure 7. Additional absorption DRIFTS spectra in TVT ZnO powder samples. $\Delta \mathrm{R}=\mathrm{TVT} \_5 \% \mathrm{Ac} /$ ZnO-TVT_2.5\%Ac/ZnO and TVT_2.5\%Ac/ZnO-TVT_0.5\%Ac/ZnO.

\subsection{The Effect of Activator Introduction Method on the ZnO CSP/SPS Process}

Table 2 presents data on the average grain size and relative density of CSP samples. The mean powder particle size D (data from Table 1) and mean grain size $G$ of ceramic samples are given according to the results of the analysis of the SEM images.

Table 2. Relative density and grain sizes of CSP samples.

\begin{tabular}{ccccc}
\hline Sample & $\begin{array}{c}\text { Zn(Ac) } \\
\text { Introduction } \\
\text { Method }\end{array}$ & $\begin{array}{c}\text { Mean Powder } \\
\text { Particle Size } \\
\mathbf{D}, \boldsymbol{\mu m}\end{array}$ & $\begin{array}{c}\text { Mean Grain } \\
\text { Size G, } \boldsymbol{\mu m}\end{array}$ & $\begin{array}{c}\text { Relative } \\
\text { Density } \boldsymbol{\rho}\end{array}$ \\
\hline CS_ZnO $+\mathrm{H}_{2} \mathrm{O}$ & $\begin{array}{c}\text { injecting the } \\
\text { DI water }\end{array}$ & $0.193 \pm 0.002$ & $0.193 \pm 0.002$ & 0.63 \\
\hline CS_0.5\%Ac/ZnO & & $0.181 \pm 0.002$ & $0.530 \pm 0.014$ & 0.84 \\
CS_2.5\%Ac/ZnO & impregnation & $0.194 \pm 0.003$ & $0.346 \pm 0.004$ & 0.93 \\
CS_5\%Ac/ZnO & & $0.194 \pm 0.002$ & $0.330 \pm 0.004$ & 0.97 \\
\hline CS_TVT-0.5\%Ac/ZnO & impregnation $+\mathrm{TVT}$ & $0.369 \pm 0.004$ & $0.380 \pm 0.004$ & 0.60 \\
CS_TVT-2.5\%Ac/ZnO & 0.006 & $0.383 \pm 0.01$ & 0.65 \\
CS_TVT-5\%Ac/ZnO & & $0.444 \pm 0.007$ & $0.520 \pm 0.007$ & 0.87 \\
\hline CS_ZnO $+\mathrm{H}_{2} \mathrm{O}-0.5 \% \mathrm{Zc}$ & injecting & $0.193 \pm 0.002$ & $0.191 \pm 0.002$ & 0.76 \\
\hline
\end{tabular}

SEM images of samples microstructures obtained from impregnated powders and subjected to TVT are shown in Figure 8.

The relative density of samples increases with the increasing $\mathrm{Zn}(\mathrm{Ac})_{2}$ concentration both when using the impregnation method and TVT. At the same time, the average grain size has different tendencies to change depending on the $\mathrm{Zn}(\mathrm{Ac})_{2}$ concentration for different activator introduction methods. When using TVT, there is a direct dependence, and when impregnating, the opposite is observed. The $\mathrm{Zn}(\mathrm{Ac})_{2}$ introduction in an aqueous solution with a syringe directly into a mold with a pre-pressed powder (sample CS_ZnO $+\mathrm{H}_{2} \mathrm{O}$ $0.5 \% \mathrm{Ac}$ ) does not give a pronounced effect with respect to the grain size, since there is actually a marked effect in terms of relative density under the conditions of this experiment (pressure $80 \mathrm{MPa}$, heating-dwell cycle about $7 \mathrm{~min}$ ), even in comparison with the sample 
(CS_ZnO $+\mathrm{H}_{2} \mathrm{O}$ ) obtained using deionized water without any $\mathrm{Zn}(\mathrm{Ac})_{2}$ addition (Figure 9). However, although the range of grain sizes and their average size $G$ do not change, there are differences in the distribution of grain sizes into components. Samples with different introduction methods and the same amount of activating additive-CS_0.5\%Ac/ZnO and $\mathrm{CS} \_\mathrm{ZnO}+\mathrm{H}_{2} \mathrm{O}-0.5 \%$ Ac differ especially strongly in microstructure and grain size (Figure 9). Probably, since after impregnation, $\mathrm{Zn}(\mathrm{Ac})_{2}$ is bound in the crystal structure, and after evaporation and extrusion of excess water from the mold, CSP continues in water vapor, almost without reducing activator content. When the solution is added to the mold after its partial evaporation and extrusion in a place with water, a certain amount of $\mathrm{Zn}(\mathrm{Ac})_{2}$ is lost, and CSP continues under conditions of a reduced activator content, which leads to a restriction of grain growth and a decrease in relative density.

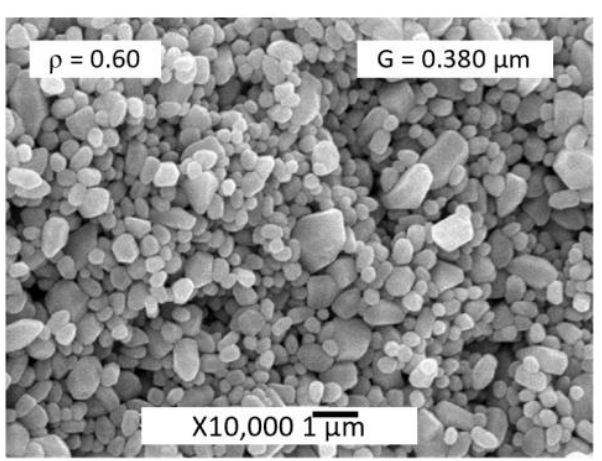

(a)

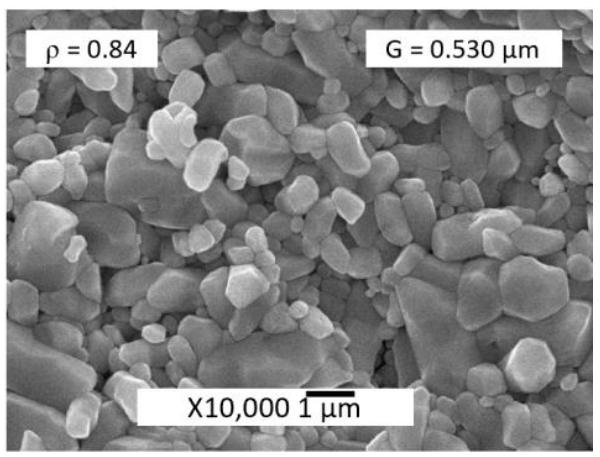

(d)

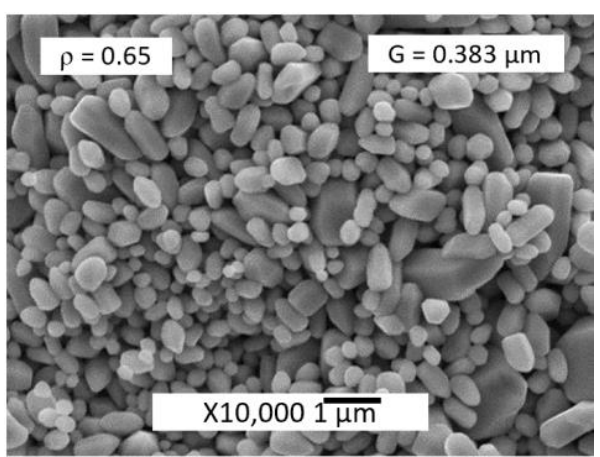

(b)

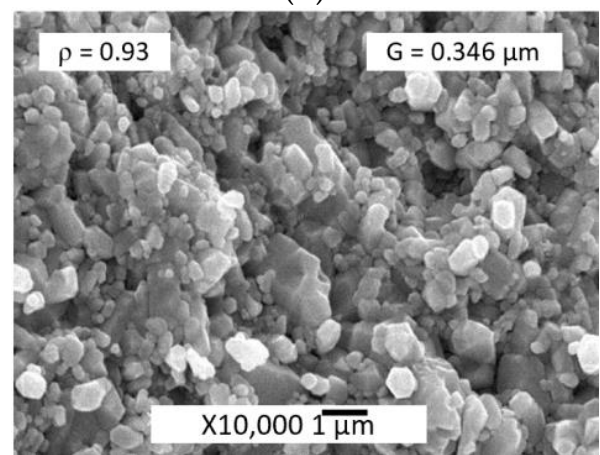

(e)

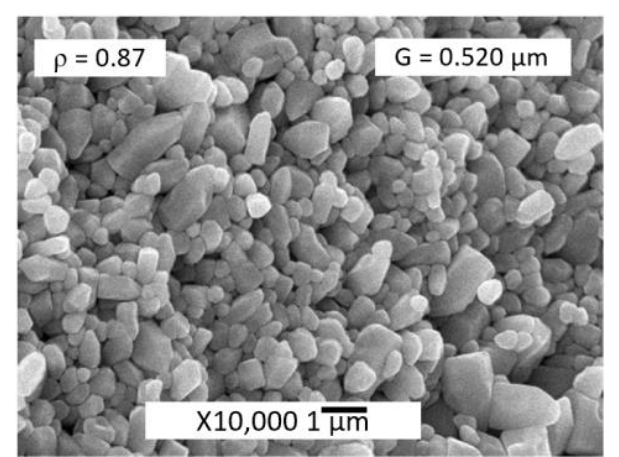

(c)

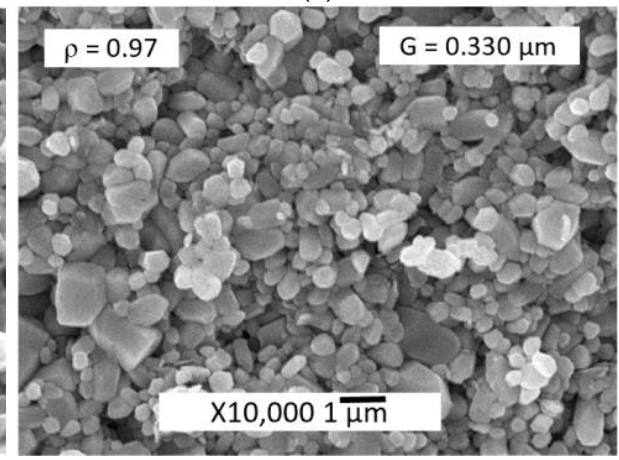

(f)

Figure 8. SEM images of the ZnO CSP samples microstructure: CS_TVT-0.5\%Ac/ZnO (a), CS_TVT-2.5\%Ac/ZnO (b), CS_TVT-5\%Ac/ZnO (c), CS_0.5\%Ac/ZnO (d), CS_2.5\%Ac/ZnO (e), and CS_5\%Ac/ZnO (f).

Figure 10 shows the time-dependent relative density curves for each CSP sample and the CSP/SPS process stages. The impregnated and impregnated + TVT groups of CSP samples are shown in different colors. The dependencies of the relative density on the sintering time have a non-monotonic character, reflecting the processes occurring with an increase in the temperature and pressure. The stepwise stages of compaction visible in Figure 10 require study with a more detailed registration. At the moment, there are separate attempts to explain them in $[25,27]$. 

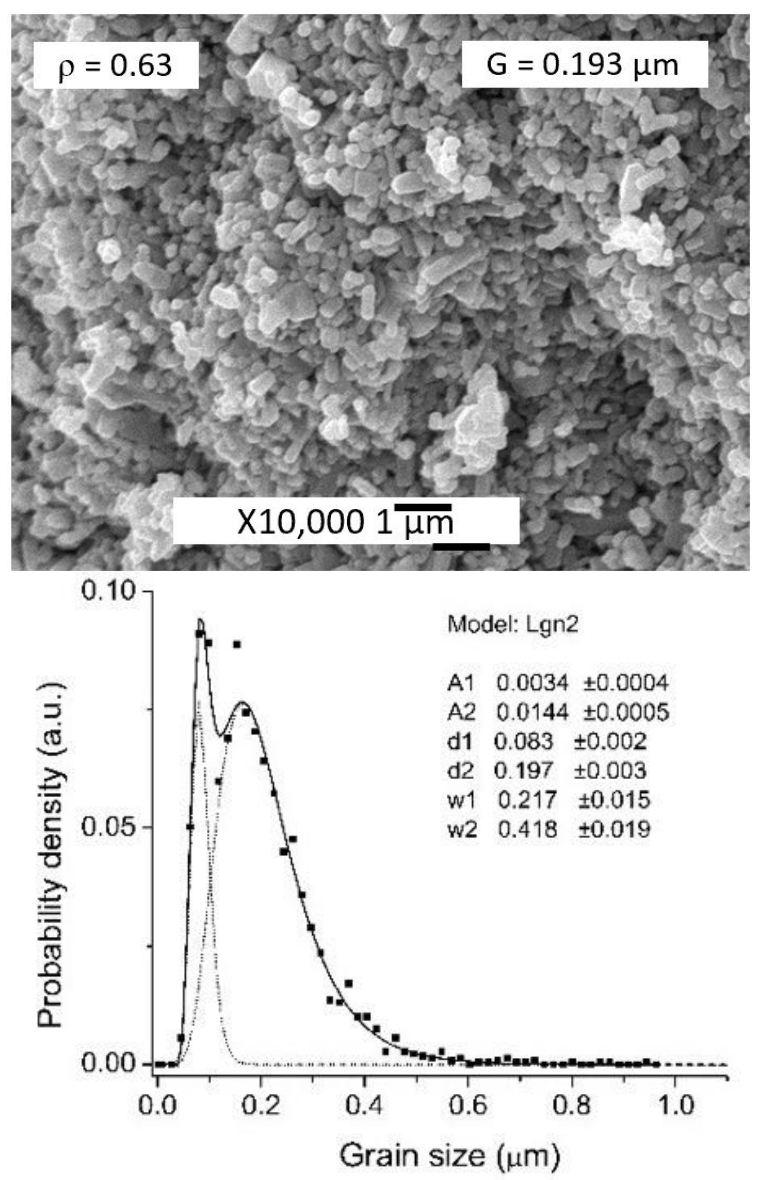

(a)
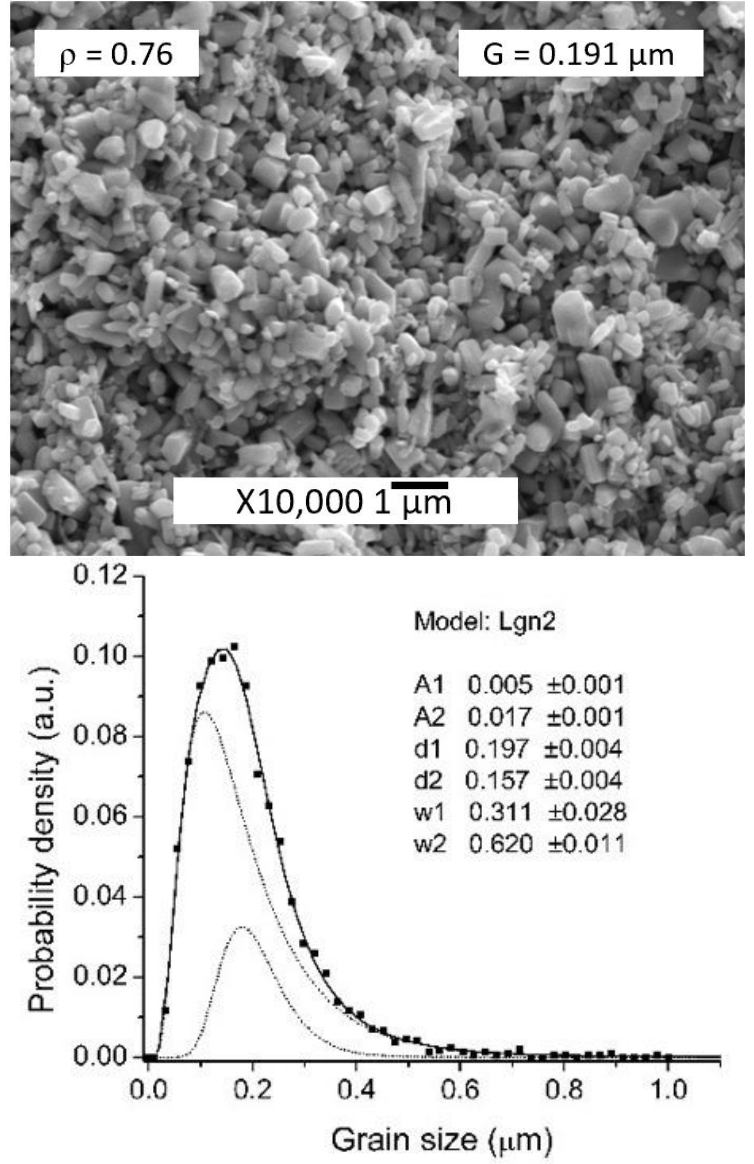

(b)

Figure 9. SEM images of microstructure and grain size distribution of the CS_ZnO $+\mathrm{H}_{2} \mathrm{O}(\mathbf{a})$ and CS_ZnO $+\mathrm{H}_{2} \mathrm{O}-0.5 \% \mathrm{Ac}$ (b) CSP samples. The grain size distribution is calculated from the respective SEM images.

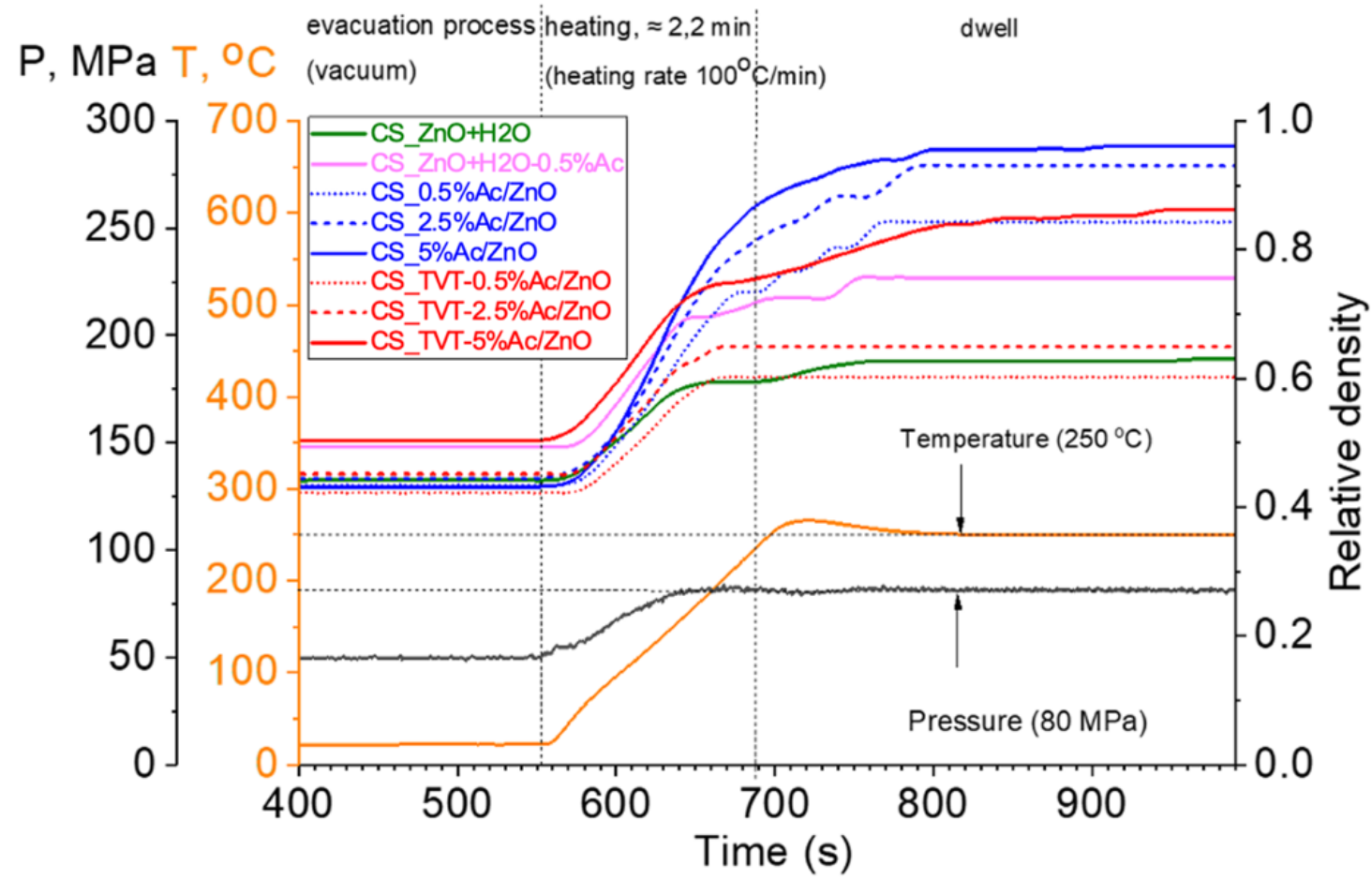

Figure 10. The time-dependent relative density curves of the ZnO CSP samples and the CSP/SPS process stages. 
In comparison with the traditional approach to CSP, the SPS method has several distinctive features. An important stage of the process is the air evacuation process (vacuum). A stable process was achieved when vacuuming to 0.23 mbar pressure. At a higher pressure and, accordingly, a short evacuation time, the air is quickly removed from the mold, but the water does not have time to evaporate and occupies all the free space. Then, with rapid heating, the water expands almost instantly, leading to the mold's destruction. At a pressure in the SPS chamber of $0.23 \mathrm{mbar}$, reached in $8 \mathrm{~min}$, part of the water evaporates through the gaps between the graphite foil and the punches and, due to the freed space in the die, the vapor pressure is maintained, which is in equilibrium with liquid water. As a result, CSP flows stably partly in the medium of saturated water vapor and partly in the medium of preserved condensed water. The cooling stage is also crucial due to the rapid free cooling of the mold under SPS conditions. In some experiments, cracks were formed during the CSP/SPS samples from impregnated $\mathrm{ZnO}$ powder (CS_2.5\%Ac/ZnO and CS_5\%Ac/ZnO). Additional studies are required to determine the optimal modes of the cooling stage.

\section{Discussion}

According to the data of Table 2 and Figure 8, the use of $\mathrm{ZnO}$ powder with preapplied $\mathrm{Zn}(\mathrm{Ac})_{2}$ by the impregnation method leads to the best CSP results (under the conditions of this study). This fact can be explained by the appearance of solid-phase mobility of the impregnated $\mathrm{ZnO}$ powder's crystal structure during a long time (12 h) drying at a $70{ }^{\circ} \mathrm{C}$, as evidenced by changes in the PSD components. At the same time, according to IR spectroscopy data (Figures 6 and 7), the interaction with water leads to the hydroxylation of $\mathrm{ZnO}$ crystals, the adsorption of acetate ions, ions destruction into smaller groups, and subsequent diffusion into the volume of $\mathrm{ZnO}$ crystals. Thus, solid-phase mobility appears due to the exchange of water molecules and acetate ions between crystals and the environment [21]. At the impregnation temperature of $\sim 70{ }^{\circ} \mathrm{C}$, the exchange rate is low, the solid-phase mobility of the structure and the processes associated with it are in the initial stage of development. With TVT, the processes of exchange with the environment and the solid-phase mobility and transformation of the crystal structure are significantly accelerated. A similar acceleration occurs under CSP conditions but with the action of mechanical pressure.

The time-dependent relative density curves of the ZnO CSP samples have a complex form (Figure 10). The non-monotonic character is associated with the consumption of thermal energy for the processes taking place, the main of which are water evaporation, decomposition of the additive $\mathrm{Zn}(\mathrm{Ac})_{2}$, and sintering, which includes mass transfer, and, probably, the solid-phase mobility of the $\mathrm{ZnO}$ crystal structure. In all cases, due to the ratio of a small amount of water (1.6\%) and the mass of $\mathrm{ZnO}$ powder, the effect of water evaporation is small and can be ignored. In the samples CS_ $\mathrm{ZnO}+\mathrm{H}_{2} \mathrm{O}$ and $\mathrm{ZnO}+$ $0.5 \% \mathrm{Ac}-\mathrm{H}_{2} \mathrm{O}$, densification is minimal, mechanical pressure leads to compaction of the powders, then with an increase in temperature and during dwelling, the density does not change or increases slightly $\left(\mathrm{ZnO}+0.5 \% \mathrm{Ac}-\mathrm{H}_{2} \mathrm{O}\right)$. In the group of samples after TVT, only traces of $\mathrm{Zn}(\mathrm{Ac})_{2}$ are present, and the effect of its decomposition on the dependencies of density changes is not observed. The kinks of dependencies reflect the sintering processes. However, they are affected by the slow setting of the temperature. This is due to the fact that the mold heats up quickly, and the powder mass ( $3 \mathrm{~g}$ ) warms up more slowly, and as it heats up, the stages of increasing the density of samples are activated.

Due to the preliminary activation of the crystal structure under impregnation conditions, the acceleration of mass transfer in a short time of CSP/SPS (used in this work) leads to the formation of a dense microstructure of ceramic samples (Figure $8 \mathrm{~d}-\mathrm{f}$ ). The decrease in the size of ceramic grains (samples CS_0.5\%Ac/ZnO, CS_2.5\%Ac/ZnO, CS_5\%Ac/ZnO in Table 2) is probably due to the inhibition of mass transfer by the impurity phase of the LBZA, the lifetime of which (between formation and decomposition) increases with an increase in the $\mathrm{Zn}(\mathrm{Ac})_{2}$ content in the initial $\mathrm{ZnO}$ powder. However, under these condi- 
tions, the solid-phase mobility of the crystal structure and the ability to change their shape (deformation) increases. As a result, a dense microstructure with small grains is formed.

During a long period of TVT ( $20 \mathrm{~h}$ in this work), the crystal structure of $\mathrm{ZnO}$ powder is transformed under the action of solid-phase mobility: the crystal size of powder samples increases. In addition, solid-phase mobility leads to a decrease in the number of defects in the crystal structure. As a result of the improvement of the crystal structure, its solidphase mobility decreases, and crystal growth stops. The conclusion about improving the structure at a certain stage of TVT is made based on several signs. When crystals are formed under these conditions, the sizes of coherent scattering regions increase [39-41] the content of hydroxyl groups decreases [41-44] and well-defined crystals with flat sides and sharp edges appear [41,42]. CSP at $250^{\circ} \mathrm{C}$ with the addition of deionized water leads to compaction without noticeable signs of powder particles sintering after TVT (samples CS_TVT-0.5\%Ac/ZnO and CS_TVT-2.5\%Ac/ZnO (Figure 8a,b, Table 2)). However, when the $\mathrm{Zn}(\mathrm{Ac})_{2}$ content increases from 0.5 up to $5 \%$ in the crystal structure of $\mathrm{ZnO}$ powder after TVT, more residual activator forms (LBZA) remain (Figure 5a), which leads to their release into the aqueous medium and the appearance of exchange processes between the medium and $\mathrm{ZnO}$ crystals in the CSP process. Exchange processes with the medium activate solidstate structural mobility and mass transfer, which leads to the increased relative density of ceramic samples (Figure 8a-c, Table 2). Furthermore, under these conditions, the LBZA phase is absent, and the growth of ceramic grains is observed (Table 2). As a result, the sample CS_TVT-5\%Ac/ZnO (Figure 8c) is characterized by significant grain growth and dense microstructure formed in a short time CSP, which shows a high intensity of exchange of molecular groups between crystals and the aqueous medium.

CSP $\mathrm{ZnO}$ without an activator with the addition of deionized water (sample CS_ZnO $+\mathrm{H}_{2} \mathrm{O}$ ) does not lead to rapid densification (Figure 9a). A change in the PSD compared to Figure $2 \mathrm{a}$, shows that the differentiation of crystals into components begins in these conditions, but the size range and average size $\mathrm{D}$ of the crystals do not change. Long dwell time under these conditions may lead to densification caused by activating influence of some technological impurities (acids and oxidizing agents) in graphite foil, which could get into the foil during manufacture process [18].

The weak sintering effect of sample CS_ZnO $+\mathrm{H}_{2} \mathrm{O}-0.5 \%$ Ac with the injection of $0.5 \%$ $\mathrm{Zn}(\mathrm{Ac})_{2}$ solution directly to the mold (Figure $9 \mathrm{~b}$ ) can be associated with the short time of the CSP, during which the solid-state structural mobility did not do so have time to develop. However, the differentiation of crystals took place to a greater extent than in a water medium without an activator (Figure 9a).

A rapid process in the CSP/SPS reveals a difference in the influence of the solid-state structure mobility of the mass transfer. In long-term CSP processes (without SPS rapid heating), no difference between impregnation or injecting methods of additive introduction was observed [20]. The effect of changing the method of $\mathrm{Zn}(\mathrm{Ac})_{2}$ introducing and its concentration under CSP/SPS conditions, taking into account the mechanical pressure and the holding time, can be estimated compared to the results obtained by the other authors (Table 3). It is worth noting that in [14] a mechanical pressure of $150 \mathrm{MPa}$ was required to achieve a relative density of 0.97 compared to $80 \mathrm{MPa}$ used in this study to achieve the same density. This result is due to the fact that an increase in mechanical pressure accelerates surface diffusion due to the formation of defects caused by gradients of mechanical stresses [14]. Furthermore, the high density achieved in work [18] for CSP in a water medium for a long time without an additive can be associated with the action of technological impurities released from graphite foil, which is mentioned above.

The results of comparing the data in Table 3 lead to three practically important statements and assumptions:

1. The impregnation of $\mathrm{ZnO}$ powder by $\mathrm{Zn}(\mathrm{Ac})_{2}$ allows reducing the mechanical pressure from $150 \mathrm{MPa}$ to at least $80 \mathrm{MPa}$ while maintaining the same CSP/SPS process short time (about $7 \mathrm{~min}$ ) and achieving the high relative density of 0.97 as in work [14], without using a special expensive high-strength mold. As a result, it becomes possible 
to effectively use standard SPS tools for CSP research under controlled conditions and with the possibility to vary the heating speed, holding temperature, and cooling conditions within a wide range, which is difficult or completely inaccessible when using specially assembled laboratory setups for CSP based on hand presses.

2. An increase in the content of $\mathrm{Zn}(\mathrm{Ac})_{2}$ introduced by the impregnation method in the range of $0.5,2.5,5 \mathrm{wt} . \%$ leads to an increase in the relative density of CSP samples and a simultaneous decrease in grain growth (Tables 2 and 3). This result shows the possibility to control the microstructure of ceramics due to the selection method of additive introduction even in a short time CSP/SPS approach.

3. The experimentally established possibility to reduce the pressure and the CSP time while maintaining a high relative density of ceramics due to the selection of additives introduction method have a substantial practical impact for further applied research aimed at industrial applicability of CSP.

Table 3. Effect of the additive introduction method on the characteristics of $\mathrm{ZnO}$ samples cold sintered at $250{ }^{\circ} \mathrm{C}$ using SPS equipment.

\begin{tabular}{|c|c|c|c|c|c|c|c|c|c|}
\hline $\begin{array}{l}\text { Heating } \\
\text { Rate, } \\
{ }^{\circ} \mathrm{C} / \mathrm{min}\end{array}$ & $\begin{array}{l}\text { Dwell } \\
\text { Time, } \\
\text { min }\end{array}$ & $\begin{array}{l}\text { Pressure, } \\
\mathrm{MPa}\end{array}$ & $\begin{array}{l}\text { Powder } \\
\text { Particle } \\
\text { Size }\end{array}$ & $\begin{array}{c}\mathrm{Zn}(\mathrm{Ac})_{2} \\
\text { Content, } \\
\text { wt. } \%\end{array}$ & $\begin{array}{l}\text { DI Water } \\
\text { Content, } \\
\text { wt. } \%\end{array}$ & $\begin{array}{c}\mathrm{Zn}(\mathrm{Ac})_{2} \text { Introduction } \\
\text { Method }\end{array}$ & $\begin{array}{c}\text { Mean } \\
\text { Grain Size, } \\
\mu \mathrm{m}\end{array}$ & $\begin{array}{l}\text { Relative } \\
\text { Density }\end{array}$ & References \\
\hline 100 & 5 & 80 & $0.212 \mu \mathrm{m}$ & 0.5 & 1.6 & $\begin{array}{c}\text { impregnation } \\
\left(\mathrm{CS} \_0.5 \% \mathrm{Ac} / \mathrm{ZnO}\right)\end{array}$ & 0.530 & 0.84 & This work \\
\hline 100 & 5 & 80 & $0.243 \mu \mathrm{m}$ & 5 & 1.6 & $\begin{array}{c}\text { impregnation } \\
(\mathrm{CS} 55 \% \mathrm{Ac} / \mathrm{ZnO})\end{array}$ & 0.330 & 0.97 & This work \\
\hline 100 & 5 & 80 & $0.193 \mu \mathrm{m}$ & 0.5 & 1.6 & $\begin{array}{c}\text { injecting the solution } \\
\left(\mathrm{CS} \_\mathrm{ZnO}+\right. \\
\left.\mathrm{H}_{2} \mathrm{O}-0.5 \% \mathrm{Ac}\right)\end{array}$ & 0.191 & 0.76 & This work \\
\hline 100 & 5 & 150 & $20-50 \mathrm{~nm}$ & 0.5 & 1.6 & injecting the solution & $>0.100$ & 0.97 & [14] \\
\hline 20 & 60 & 300 & $40-100 \mathrm{~nm}$ & 0 & 3.2 & - & 0.138 & 0.99 & [18] \\
\hline
\end{tabular}

\section{Conclusions}

The influence of the $\mathrm{Zn}(\mathrm{Ac})_{2}$ introducing method on the relative density and grain size of $\mathrm{ZnO}$ ceramic samples obtained by CSP using rapid heating at an SPS equipment was studied. It was shown that the method of impregnation of the initial powder with $0.5-5 \mathrm{wt} \% \mathrm{Zn}(\mathrm{Ac})_{2}$ allows implementing CSP at reduced mechanical pressure. $\mathrm{ZnO}$ was compacted to a high relative density (over 0.90 ) with a pronounced grain growth under $\mathrm{CSP} / \mathrm{SPS}$ conditions at a reduced pressure of $80 \mathrm{MPa}$, a high heating rate of $100^{\circ} \mathrm{C} / \mathrm{min}$, and a short dwell time of $5 \mathrm{~min}$ at a temperature of $250{ }^{\circ} \mathrm{C}$. Due to the preliminary activation (saturation with defects) of the structure of $\mathrm{ZnO}$ crystalline powder particles under impregnation conditions, an acceleration of mass transfer in a short time of CSP/SPS is observed, which leads to the formation of a dense microstructure of ceramic samples. The decrease in the size of ceramic grains with an increase in the content of $\mathrm{Zn}(\mathrm{Ac})_{2}$ is probably due to the restriction of mass transfer by the impurity phase of the LBZA, the duration of which increases with the increase in the content of $\mathrm{Zn}(\mathrm{Ac})_{2}$ in the reaction medium. However, under these conditions, the $\mathrm{ZnO}$ crystal structure solid-phase mobility and the ability to change their shape increases. As a result, a dense microstructure with small grains was formed.

The introduction of $\mathrm{Zn}(\mathrm{Ac})_{2}$ using impregnation and subsequent TVT leads to the growth of $\mathrm{ZnO}$ powder particles, the ordering and improving of their structure, and a decrease in its solid-phase mobility. However, CSP of TVT ZnO powder under conditions of reduced pressure and rapid heating and short time dwell with the addition of deionized water leads to compaction without noticeable signs of particle sintering.

The weak effect of sintering $\mathrm{ZnO}$ with the addition of an aqueous solution of $0.5 \mathrm{wt} . \%$ $\mathrm{Zn}(\mathrm{Ac})_{2}$ directly into the mold caused to the short CSP time (about $7 \mathrm{~min}$ ), during which the structural mobility did not have time to develop, and the low mechanical pressure, 
which is not enough to accelerate surface diffusion due to the formation of defects caused by mechanical stress gradients.

The ability to reduce the mechanical pressure and CSP time while maintaining a high relative density of ceramics using the selection of additives introduction method has a substantial practical impact for further applied research aimed at industrial applicability of CSP.

Author Contributions: Conceptualization, Y.D.I., A.V.S., N.W.S.P., A.S. and S.N.G.; data curation, Y.D.I., A.V.S., A.Y.K., A.N.K., A.S. and S.N.G.; formal analysis, Y.D.I., A.V.S., A.Y.K., A.N.K. and A.S.; investigation, Y.D.I., A.V.S., A.N.K., N.W.S.P. and A.S.; methodology, Y.D.I. and N.W.S.P.; visualization, A.Y.K.; writing—original draft, Y.D.I., A.V.S. and A.Y.K.; writing—review and editing, N.W.S.P. and A.S. All authors have read and agreed to the published version of the manuscript.

Funding: The work of Alexandra Yu. Kurmysheva, Nestor Washington Solís Pinargote, and Anton Smirnov was supported by the Ministry of Science and Higher Education of the Russian Federation under project 0707-2020-0034.

Institutional Review Board Statement: Not applicable.

Informed Consent Statement: Not applicable.

Data Availability Statement: The data presented in this study are available on request from the corresponding author after obtaining the permission of an authorized person.

Acknowledgments: The study was carried out on the equipment of the Center of collective use of MSUT "STANKIN" (project 075-15-2021-695), and of the Shared Science and Training Center for Collective Use RTU MIREA and supported by the Ministry of Science and Higher Education of the Russian Federation. The work of Andrey N. Kharlanov was carried out within the framework of the state budget theme No. AAAA-A21-121011990019-4 "Surface physicochemistry, adsorption and catalysis" and was supported in part by M.V. Lomonosov Moscow State University Program of Development. Yurii D. Ivakin and Andrey V. Smirnov thank the RTU MIREA (initiative research "Ceramics Synthesis") for their support.

Conflicts of Interest: The authors declare no conflict of interest.

\section{References}

1. Cologna, M.; Rashkova, B.; Raj, R. Flash sintering of nanograin zirconia in $<5 \mathrm{~s}$ at $850{ }^{\circ} \mathrm{C}$. J. Am. Ceram. Soc. 2010, 93, 3556-3559. [CrossRef]

2. Grigoriev, S.; Peretyagin, P.; Smirnov, A.; Solís, W.; Díaz, L.A.; Fernandez, A.; Torrecillas, R. Effect of graphene addition on the mechanical and electrical properties of $\mathrm{Al}_{2} \mathrm{O}_{3}-\mathrm{SiCw}$ ceramics. J. Eur. Ceram. Soc. 2017, 37, 2473-2479. [CrossRef]

3. Smirnov, A.; Peretyagin, P.; Bartolomé, J.F. Processing and mechanical properties of new hierarchical metal-graphene flakes reinforced ceramic matrix composites. J. Eur. Ceram. Soc. 2019, 39, 3491-3497. [CrossRef]

4. Smirnov, A.; Seleznev, A.; Solís Pinargote, N.W.; Pristinskiy, Y.; Peretyagin, P.; Bartolomé, J.F. The Influence of Wire Electrical Discharge Machining Cutting Parameters on the Surface Roughness and Flexural Strength of $\mathrm{ZrO}_{2} /$ TiN Ceramic Nanocomposites Obtained by Spark Plasma Sintering. Nanomaterials 2019, 9, 1391. [CrossRef]

5. Muche, D.N.F.; Drazin, J.W.; Mardinly, J.; Dey, S.; Castro, R.H.R. Colossal grain boundary strengthening in ultrafine nanocrystalline oxides. Mater. Lett. 2017, 186, 298-300. [CrossRef]

6. Guo, J.; Guo, H.; Baker, A.L.; Lanagan, M.T.; Kupp, E.R.; Messing, G.L.; Randall, C.A. Cold Sintering: A Paradigm Shift for Processing and Integration of Ceramics. Angew. Chem. 2016, 55, 11457-11461. [CrossRef] [PubMed]

7. European Comission. Ceramic Manufacturing Industry. Eur. Commun. 2007, 210-211. Available online: https://eippcb.jrc.ec. europa.eu/sites/default/files/2019-11/cer_bref_0807.pdf (accessed on 2 November 2021).

8. Ibn-Mohammed, T.; Randall, C.A.; Mustapha, K.B.; Guo, J.; Walker, J.; Berbano, S.; Reaney, I.M. Decarbonising ceramic manufacturing: A techno-economic analysis of energy efficient sintering technologies in the functional materials sector. J. Eur. Ceram. Soc. 2019, 39, 5213-5235. [CrossRef]

9. Biesuz, M.; Grasso, S.; Sglavo, V.M. What's new in ceramics sintering? A short report on the latest trends and future prospects. Curr. Opin. Solid State Mater. Sci. 2020, 24, 100868. [CrossRef]

10. Sohrabi Baba Heidary, D.; Lanagan, M.; Randall, C.A. Contrasting energy efficiency in various ceramic sintering processes. J. Eur. Ceram. Soc. 2018, 38, 1018-1029. [CrossRef]

11. Maria, J.P.; Kang, X.; Floyd, R.D.; Dickey, E.C.; Guo, H.; Guo, J.; Baker, A.; Funihashi, S.; Randall, C.A. Cold sintering: Current status and prospects. J. Mater. Res. 2017, 32, 3205-3218. [CrossRef] 
12. Yamasaki, N.; Yanagisawa, K.; Nishioka, M.; Kanahara, S. A hydrothermal hot-pressing method: Apparatus and application. J. Mater. Sci. Lett. 1986, 5, 355-356. [CrossRef]

13. Guo, J.; Floyd, R.; Lowum, S.; Maria, J.-P.; Herisson de Beauvoir, T.; Seo, J.-H.; Randall, C.A. Cold Sintering: Progress, Challenges, and Future Opportunities. Annu. Rev. Mater. Res. 2019, 49, 275-295. [CrossRef]

14. Gonzalez-Julian, J.; Neuhaus, K.; Bernemann, M.; da Silva, J.P.; Laptev, A.; Bram, M.; Guillon, O. Unveiling the mechanisms of cold sintering of $\mathrm{ZnO}$ at $250{ }^{\circ} \mathrm{C}$ by varying applied stress and characterizing grain boundaries by Kelvin Probe Force Microscopy. Acta Mater. 2018, 144, 116-128. [CrossRef]

15. Bang, S.H.; Tsuji, K.; Ndayishimiye, A.; Dursun, S.; Seo, J.H.; Otieno, S.; Randall, C.A. Toward a size scale-up cold sintering process at reduced uniaxial pressure. J. Am. Ceram. Soc. 2020, 103, 2322-2327. [CrossRef]

16. Ndayishimiye, A.; Sengul, M.Y.; Bang, S.H.; Tsuji, K.; Takashima, K.; de Beauvoir, T.H.; Denux, D.; Thibaud, J.-M.; van Duin, A.C.; Elissalde, C.; et al. Comparing hydrothermal sintering and cold sintering process: Mechanisms, microstructure, kinetics and chemistry. J. Eur. Ceram. Soc. 2020, 40, 1312-1324. [CrossRef]

17. Serrano, A.; Caballero-Calero, O.; García, M.Á.; Lazić, S.; Carmona, N.; Castro, G.R.; MarisolMartín-González, M.; Fernández, J.F. Cold sintering process of $\mathrm{ZnO}$ ceramics: Effect of the nanoparticle/microparticle ratio. J. Eur. Ceram. Soc. 2020, 40, 5535-5542. [CrossRef]

18. Nur, K.; Mishra, T.P.; da Silva, J.G.P.; Gonzalez-Julian, J.; Bram, M.; Guillon, O. Influence of powder characteristics on cold sintering of nano-sized $\mathrm{ZnO}$ with density above 99\%. J. Eur. Ceram. Soc. 2021, 41, 2648-2662. [CrossRef]

19. Kang, X.; Floyd, R.; Lowum, S.; Long, D.; Dickey, E.; Maria, J.P. Cold sintering with dimethyl sulfoxide solutions for metal oxides. J. Mater. Sci. 2019, 54, 7438-7446. [CrossRef]

20. Ivakin, Y.D.; Smirnov, A.V.; Tarasovskii, V.P.; Rybal'Chenko, V.V.; Vasin, A.A.; Kholodkova, A.A.; Kormilitsin, M.N. Cold sintering of $\mathrm{ZnO}$ ceramic in water medium: Test demonstration. Glass Ceram. 2019, 76, 210-215. [CrossRef]

21. Ivakin, Y.; Smirnov, A.; Kholodkova, A.; Vasin, A.; Kormilicin, M.; Kornyushin, M.; Stolyarov, V. Comparative Study of Cold Sintering Process and Autoclave Thermo-Vapor Treatment on a ZnO Sample. Crystals 2021, 11, 71. [CrossRef]

22. Funahashi, S.; Guo, J.; Guo, H.; Wang, K.; Baker, A.L.; Shiratsuyu, K.; Randall, C.A. Demonstration of the cold sintering process study for the densification and grain growth of ZnO ceramics. J. Am. Ceram. Soc. 2017, 100, 546-553. [CrossRef]

23. Ivakin, Y.; Smirnov, A.; Kormilitsin, M.; Kholodkova, A.; Vasin, A.; Kornyushin, M.; Tarasovskii, V.; Rybalchenko, V. Effect of mechanical pressure on zinc oxide recrystallization in aqueous medium during cold sintering. Russ. J. Phys. Chem. B 2022, in press.

24. Kuzin, V.V.; Grigoriev, S.N.; Volosova, M.A. The role of the thermal factor in the wear mechanism of ceramic tools: Part 1. Macrolevel. J. Frict. Wear 2014, 35, 505-510. [CrossRef]

25. Ndayishimiye, A.; Fan, Z.; Funahashi, S.; Randall, C.A. Assessment of the Role of Speciation during Cold Sintering of ZnO Using Chelates. Inorg. Chem. 2021, 60, 13453-13460. [CrossRef] [PubMed]

26. Grasso, S.; Biesuz, M.; Zoli, L.; Taveri, G.; Duff, A.I.; Ke, D.; Jiang, A.; Reece, M.J. A review of cold sintering processes. Adv. Appl. Ceram. 2020, 119, 115-143. [CrossRef]

27. Floyd, R.D.; Lowum, S.; Maria, J.P. Cold sintering zinc oxide with a crystalline zinc acetate dihydrate mass transport phase. J. Mater. Sci. 2020, 55, 15117-15129. [CrossRef]

28. Dargatz, B.; Gonzalez-Julian, J.; Bram, M.; Jakes, P.; Besmehn, A.; Schade, L.; Röder, R.; Ronning, C.; Guillon, O. FAST/SPS sintering of nanocrystalline zinc oxide-Part I: Enhanced densification and formation of hydrogen-related defects in presence of adsorbed water. J. Eur. Ceram. Soc. 2016, 36, 1207-1220. [CrossRef]

29. Dargatz, B.; Gonzalez-Julian, J.; Bram, M.; Shinoda, Y.; Wakai, F.; Guillon, O. FAST/SPS sintering of nanocrystalline zinc oxide-Part II: Abnormal grain growth, texture and grain anisotropy. J. Eur. Ceram. Soc. 2016, 36, 1221-1232. [CrossRef]

30. Sengul, M.Y.; Guo, J.; Randall, C.A.; van Duin, A.C. Water-Mediated Surface Diffusion Mechanism Enables the Cold Sintering Process: A Combined Computational and Experimental Study. Angew. Chem. 2019, 58, 12420-12424. [CrossRef]

31. Tarat, A.; Nettle, C.J.; Bryant, D.T.J.; Jones, D.R.; Penny, M.W.; Brown, R.A.; Majitha, R.; Meissner, K.E.; Maffeis, T.G.G. Microwaveassisted synthesis of layered basic zinc acetate nanosheets and their thermal decomposition into nanocrystalline ZnO. Nanoscale Res. Lett. 2014, 9, 11. [CrossRef] [PubMed]

32. Ivakin, Y.D.; Danchevskaya, M.N. Analysis of Recrystallization of Fine-Crystalline Corundum in a Supercritical Water Medium Using the Lognormal Particle Size Distribution Function. Russ. J. Phys. Chem. B. 2018, 12, 1205-1211. [CrossRef]

33. German, R.M. Prediction of sintered density for bimodal powder mixtures. Metall. Trans. A 1992, 23, 1455-1465. Available online: https:/ /link.springer.com/content/pdf/10.1007/BF02647329.pdf (accessed on 2 November 2021). [CrossRef]

34. Shi, Y.; Zhang, Y. Simulation of random packing of spherical particles with different size distributions. Appl. Phys. A 2008, 92, 621-626. [CrossRef]

35. Noei, H.; Qiu, H.; Wang, Y.; Löffler, E.; Wöll, C.; Muhler, M. The identification of hydroxyl groups on ZnO nanoparticles by infrared spectroscopy. Phys. Chem. Chem. Phys. 2008, 10, 7092-7097. [CrossRef]

36. Zhang, Y.; Zhu, F.; Zhang, J.; Xia, L. Converting layered zinc acetate nanobelts to one-dimensional structured ZnO nanoparticle aggregates and their photocatalytic activity. Nanoscale Res. Lett. 2008, 3, 201-204. [CrossRef]

37. Smith, B.C. The Carbonyl Group, Part V: Carboxylates-Coming Clean. Spectroscopy 2018, 33, 20-23. Available online: https: //www.spectroscopyonline.com/view/carbonyl-group-part-v-carboxylates-coming-clean (accessed on 2 November 2021). 
38. Ivakin, Y.D.; Danchevskaya, M.N.; Muravieva, G.P. Recrystallization of Zinc Oxide in a Sub-and Supercritical Water Medium. Russ. J Phys. Chem. B 2019, 13, 1189-1200. [CrossRef]

39. Danchevskaya, M.N.; Torbin, S.N.; Muravieva, G.P.; Ovchinnikova, O.G.; Ivakin, Y.D. Synthesis and investigation of crystalline modifications of silicon dioxide. React. Solids 1988, 5, 293-303. [CrossRef]

40. Danchevskaya, M.N.; Ivakin, Y.D.; Muravieva, G.P.; Luchkov, I.V. Synthesis and doping of fine-crystalline corundum in sub- and supercritical conditions. J. Phys. Conf. Ser. 2008, 121, 082001. [CrossRef]

41. Maryashkin, A.V.; Ivakin, Y.u.D.; Danchevskaya, M.N.; Murav'eva, G.P.; Kirikova, M.N. Synthesis of Corundum Doped with Cerium in Supercritical Water Fluid. Mosc. Univ. Chem. Bull. 2011, 66, 290-298. [CrossRef]

42. Danchevskaya, M.N.; Ivakin, Y.D.; Torbin, S.N.; Panasyuk, G.P.; Belan, V.N.; Voroshilov, I.L. Scientific basis of technology of finecrystalline quartz and corundum. High Press. Res. Int. J. 2001, 20, 229-239. [CrossRef]

43. Ivakin, Y.D.; Danchevskaya, M.N.; Muravieva, G.P. Kinetic model and mechanism of Y3A15O12 Formation in hydrothermal and thermovaporous synthesis. High Press. Res. 2001, 20, 87-98. [CrossRef]

44. Danchevskaya, M.N.; Ivakin, Y.D.; Torbin, S.N.; Muravieva, G.P. The role of water fluid in the formation of fine-crystalline oxide structure. J. Supercrit. Fluids 2007, 42, 419-424. [CrossRef] 